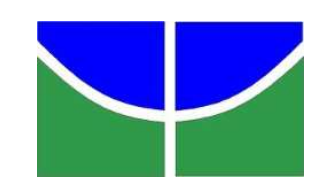

UNIVERSIDADE DE BRASÍLIA

FACULDADE DE CIÊNCIAS DA SAÚDE

PROGRAMA DE PÓS-GRADUAÇÃO EM NUTRIÇÃO HUMANA

DYANARA DE ALMEIDA OLIVEIRA

QUALIDADE E COMPORTAMENTO ALIMENTAR DE MULHERES APÓS 24 MESES OU MAIS DE CIRURGIA BARIÁTRICA

BRASÍLIA 
DYANARA DE ALMEIDA OLIVEIRA

\section{QUALIDADE E COMPORTAMENTO ALIMENTAR DE MULHERES APÓS 24 MESES OU MAIS DE CIRURGIA BARIÁTRICA}

Dissertação apresentada ao Programa de Pós-graduação em Nutrição Humana da Faculdade de Saúde da Universidade de Brasília, para obtenção do Grau de Mestre em Nutrição Humana, na área de concentração Nutrição e Doenças Crônicas não Transmissíveis

Orientadora: Prof ${ }^{\mathrm{a}}$. Dra ${ }^{\mathrm{a}}$. Kênia Mara Baiocchi de Carvalho Co-orientadora: Prof ${ }^{\mathrm{a}}$. Dr ${ }^{\mathrm{a}}$. Eliane Said Dutra 
Ficha catalográfica elaborada pela Biblioteca Central da Universidade de Brasília. Acervo 1019228.

Ol ivei ra, Dyanara de Almeida.

O48q Qualidade e camportamento al imentar de mulheres após 24 meses ou mais de cirurgia bariátrica / Dyanara de Almeida Ol iveira. -- 2014.

$87 \mathrm{f}$. : il. ; $30 \mathrm{~cm}$.

Dissertação (mestrado) - Universidade de Brasília, Faculdade de Ciências da Saúde, Programa de Pós-Graduação em Nut r ição Humana, 2014.

Orientação: Kênia Mara Baiocchi de Carvalho ; coorientação: El iane Said Dutra.

Inclui bibliografia.

1. Al imentos - Consumo. 2. Hábi tos al imentares - Mulheres. 3. Obesidade - Ci rurgia. 4. Hábitos de saúde. I. Carvalho, Kênia Mara Baiocchi de. II. Dutra, El iane Said. III. Título. 


\title{
QUALIDADE E COMPORTAMENTO ALIMENTAR DE MULHERES APÓS 24 MESES OU MAIS DE CIRURGIA BARIÁTRICA
}

Data: 09 de dezembro de 2014

\section{Banca Examinadora:}

\author{
Prof $^{\mathrm{a}}$. Dr $^{\mathrm{a}}$. Eliane Said Dutra - Presidente
}

Departamento de Nutrição - Universidade de Brasília

Prof $^{\mathrm{a}}$. Dr ${ }^{\mathrm{a}}$. Bethsaida de Abreu Soares Schmitz - Membro externo Departamento de Nutrição - Universidade de Brasília

Prof $^{\mathrm{a}}$. Dr ${ }^{\mathrm{a}}$. Karin Eleonora Sávio de Oliveira - Membro

Programa de Pós-graduação em Nutrição Humana - Universidade de Brasília

Prof $^{\mathrm{a}}$. Dr ${ }^{\mathrm{a}}$. Marina Kiyomi Ito - Suplente

Programa de Pós-graduação em Nutrição Humana - Universidade de Brasília 


\section{AGRADECIMENTOS}

$\mathrm{Na}$ realização deste trabalho várias barreiras e obstáculos precisaram ser superados ou simplesmente contornados. Gostaria de expressar meus sinceros agradecimentos aos que, sem dúvida, colaboraram direta ou indiretamente para sua realização:

Em primeiro lugar, a DEUS, a todos os Santos e aos anjos protetores que me guiam e protegem. Sempre presentes em todos os momentos de minha vida, dando-me força a cada momento, principalmente nas dificuldades, angústias e fraquezas, não me deixando desistir. Sem suas proteções, orientações e força para prosseguir nada seria possível.

Aos meus queridos e amados pais, Ed Nylson e Eliaci, por todos os ensinamentos, incentivos e amor incondicional. O apoio e o estímulo de vocês são, e sempre, serão extremamente importantes em minha vida.

À minha amada e querida avó Mundica, que esteve presente em todos os momentos desta conquista. Sem dúvida este sonho que está se realizando é fruto de suas orações, dos seus ensinamentos e incentivo. Grata pelo amor. Grata por tudo.

Aos meus avôs Raimunda, Vicente e Emidio (in memorian), pelo amor e pelos ensinamentos. Saudades eternas...

Ao meu querido tio Edilson, por todo amor, carinho, incentivo sempre presente e intensificado nesses anos de mestrado.

À Mara Rocha e Renato Lopes, pela presença constante mesmo a quilômetros de distância. Vocês foram e serão sempre fundamentais na minha vida!

Aos meus irmãos Rafael e Rodrigo, por me apoiarem sempre e por demostrarem isso nos pequenos gestos.

À Risa e sua família maravilhosa que me recebeu e acolheu tão bem. Sem dúvida o impacto da chegada em Brasília foi amortecido pelo acolhimento maravilhoso que recebi de vocês. Gratidão eterna.

A todos os meus queridos familiares (maternos e paternos) que, mesmo distantes, contribuíram significativamente para a minha formação pessoal e acadêmica, sempre me incentivando. Muito obrigada por todo apoio, cada ligação, mensagem e palavras de carinho. Sem dúvida, tem um pedacinho de cada um de vocês neste trabalho. Eternamente grata a Deus por ter e fazer parte de uma família tão maravilhosa. 
À UNB e ao Programa de Pós-Graduação em Nutrição Humana, pela acolhida e por ter-me proporcionado mais aprendizado e crescimento profissional.

À CAPES, pela bolsa de mestrado concedida, e assim permitir a realização deste sonho.

À professora Kênia, minha orientadora, pela confiança, orientação, dedicação, ensinamentos na nutrição e na vida. Admiro-a muito! Obrigada pela paciência com minhas limitações.

À minha co-orientadora, Prof ${ }^{\mathrm{a}}$. Eliane Said Dutra, serei sempre grata por tornar possível a continuidade da minha orientação e defesa. Agradeço por todo conhecimento compartilhado e a paciência com minhas limitações.

Aos membros da banca de qualificação, Prof ${ }^{\mathrm{a}}$ Eliane Said Dutra e Prof ${ }^{\mathrm{a}}$ Muriel Gubert, pelas pertinentes sugestões para aprimoramento deste trabalho.

Aos membros da banca de defesa, Prof $^{\mathrm{a}}$. Dr ${ }^{\mathrm{a}}$. Bethsáida de Abreu Soares Schmitz, Prof $^{\text {a }}$. Dr ${ }^{\mathrm{a}}$. Karin Eleonora Sávio de Oliveira e Prof ${ }^{\mathrm{a}}$. Dr ${ }^{\mathrm{a}}$. Marina Kiyomi Ito, por aceitarem participar da banca examinadora.

Às pacientes do ambulatório de obesidade do Hospital Universitário de Brasília, pela participação, disponibilidade e comprometimento com a pesquisa. Muito obrigada pela confiança e pelo aprendizado adquirido.

Às minhas companheiras do CINTOS, ERICA e VIVA, muito obrigada pelo precioso companheirismo.

À Ana Carla, por todo cuidado, apoio e carinho desde o primeiro momento, além dos conselhos e as risadas sempre presentes. Extremamente grata!

À Daniela Lopes, pela confiança e apoio desde a seleção, por dividir comigo sua pesquisa e os conhecimentos adquiridos, e também a saudade de casa e do Pará.

À Luciana Galdino, pelo seu cuidado, carinho, abraços e ombro amigo sempre presentes.

À Vivian Siqueira, pela disposição em ajudar, sempre com excelentes contribuições para o trabalho e por dividir seus conhecimentos em Estatística.

À Naiza de Sá e Neto, por todo cuidado e carinho no meu primeiro ano em Brasília e pelo incentivo sempre presente.

À Alessandra Brito, por esclarecer todas as dúvidas sobre consumo alimentar e as indicações de referências bibliográficas.

Aos alunos da graduação que sempre faziam das minhas terças-feiras, um aprendizado constante, em especial Laís, Cinndy, Andressa e Amanda. 
À Ana Spaniol, pela disposição em ajudar e por dividir seus conhecimentos sobre o SPSS.

À Adriana Barbosa, Alessandra Gaspar e Suely Barreto pela amizade e por dividir comigo a experiência de estar longe de casa. Mas, especialmente a Adriana Barbosa, pela amizade verdadeira, cuidado, carinho, por TUDO! Você, sem dúvida, acompanhou a construção deste trabalho de perto, orientou-me, acalmou-me, entendeu-me e alegrou-me muito. Muito obrigada por dividir comigo sua família e amigos! És minha amiga-irmã que Deus me presenteou no Distrito Federal. Gratidão eterna!

À Maína Pereira, por sua doçura, alegria contagiante, cuidado e carinho para comigo. Você foi fundamental no processo!

Às meninas do Tiramisú, Alessandra, Araída, Átala, Babiana, Bia, Bárbara, Camila e Maína Pereira, por compartilhar nossas vitórias, angústias e o amor de Deus. Muito obrigada por cada oração e gestos de carinho. Sempre bom estar com vocês. Vocês arrasam!

Às queridas companheiras da turma de mestrado do ano de 2012, do Programa de Pós-Graduação em Nutrição da UNB, pelo companheirismo, união e amizade. Imenso orgulho de fazer parte dessa turma.

À Tatiany Santos e à Letícia Amorim, pela companhia, cuidado, amizade e por dividir o nosso lar em Brasília.

Às amigas queridas, Pricila Luna e Isabelle Martins, por acreditarem em mim e me incentivarem a crescer profissional e pessoalmente. Em especial, à Isabelle, seu incentivo e visões do futuro são imprescindíveis à minha vida.

Aos meus queridos e grandes amigos que conquistei ao longo da vida. Sempre presentes, apesar da distância e das atividades cotidianas.

A todos que, mesmo sem saber a importância dos gestos e palavras, contribuíram para a conclusão deste trabalho e da realização deste sonho. 
O saber a gente aprende com os mestres e os livros. A sabedoria, se aprende é com a vida e com os humildes (CORA CORALINA). 


\section{RESUMO}

Introdução: Visando melhores resultados da cirurgia bariátrica, a curto e longo prazo, está disponível para comunidade modelo de pirâmide nutricional adaptada, que considera as necessidades nutricionais diferenciadas destes pacientes. $O$ presente estudo teve como objetivo avaliar o consumo e o comportamento alimentar de mulheres e investigar fatores associados à qualidade da dieta, de acordo com o modelo da pirâmide nutricional adaptada ao paciente bariátrico. Métodos: Estudo transversal, realizado com mulheres submetidas há 24 meses ou mais à gastroplastia redutora em Y-de-Roux. O questionário "três fatores alimentares" e de frequência alimentar direcionado foram aplicados para avaliação do comportamento e práticas alimentares, respectivamente. Calculou-se escore de 0 a 10 para classificação da qualidade da dieta e práticas associadas, de acordo com a pirâmide nutricional adaptada ao paciente bariátrico. Valores superiores a 5 foram considerados como hábitos satisfatórios. Aplicaram-se os testes Qui-quadrado de Pearson, $t$ de Student e regressão logística, para cálculo da odds ratio. Foi usado o programa SPSS (v.20). Resultados: Participaram do estudo 95 mulheres, onde $81,1 \%$ apresentaram hábito de vida insatisfatório, de acordo com os parâmetros da pirâmide adaptada. Entre as que apresentaram hábitos satisfatórios, o consumo de proteína, ingestão hídrica, uso de suplemento e prática de atividade física foram os elementos diferenciais de classificação. Pacientes com comportamento alimentar de restrição apresentaram maiores escores, enquanto o comportamento emocional foi maior no grupo de hábitos insatisfatórios. No modelo de regressão logística, a ausência de reganho de peso aumentou em $18 \%$ a chance de apresentar hábitos satisfatórios $(\mathrm{p}=0,001)$. Conclusão: Após 24 meses de cirurgia bariátrica a maior parte das pacientes avaliadas apresentou hábitos insatisfatórios. A ausência de reganho de peso apresentou associação significativa com hábitos saudáveis. Estes resultados apontam para importância de acompanhamento nutricional a longo prazo de pacientes bariátricos, o que pode contribuir para comportamento alimentar adequado e manutenção do peso corporal saudável entre pacientes bariátricos.

Palavras chave: Obesidade. Gastroplastia. Consumo alimentar. Comportamento alimentar. 


\begin{abstract}
Introduction: In order to guarantee the best results after bariatric surgery in the short and long term, it was proposed an adapted nutritional pyramid model, which considers the specific nutritional needs of these patients. This study aimed to evaluate the intake and the eating behavior and investigate factors associated with quality of diet, according to the model of the nutritional pyramid adapted to the bariatric patient. Methods: Cross-sectional study with women undergoing for 24 months or more to Bypass gastroplasty in Y-of-Roux. The "three food factors" and food frequency questionnaires were applied to assess the behavior and eating habits, respectively. We calculated score 0-10 for diet quality and associated practices, according to the nutritional pyramid adapted to the bariatric patient. Values greater than 5 were considered satisfactory habits. We applied the chi-square test of Pearson, Student t test and logistic regression to calculate odds ratios. We used SPSS (v.20). Results: The study included 95 women, where $81.1 \%$ presented a poor quality of eating habits and associated practices, according to the parameters of the adapted pyramid. Among those who had healthy eating habits, protein intake, water intake, supplement use and physical activity were the crucial elements for this definition. Patients with restriction of feeding behavior had higher scores, while the emotional behavior was higher in the group of poor eating habits. In the logistic regression model, the absence of regained weight increased by $18 \%$ the chance to present satisfactory habits $(p=0.001)$. Conclusion: After 24 months of bariatric surgery most of the evaluated patients had unsatisfactory habits. The absence of weight regained was significantly associated with healthy habits. These results point to the importance of nutritional long-term monitoring after bariatric surgery, which may contribute to adequate eating practices and maintaining healthy body weight among these patients.
\end{abstract}

Keywords: Obesity. Gastroplasty. Food consumption. Eating behavior. 


\section{LISTA DE FIGURAS}

Figura 1: Principais tipos de cirurgia bariátrica ….............................................. 19

Figura 2: $\quad$ Pirâmide nutricional adaptada para cirurgia bariátrica …......................... 33 


\section{LISTA DE QUADROS}

Quadro 1: Distribuição dos parâmetros avaliados

Quadro 2: Frequência diária correspondente a cada opção do questionário alimentar direcionado (QFAD)

Quadro 3: Práticas e duração de atividade física correspondente a cada tipo de atividade física 


\section{LISTA DE TABELAS}

Tabela 1: Características sociodemográficas de mulheres com 24 meses ou mais de gastroplastia redutora em Y-de-Roux, de acordo com hábitos de vida recomendados para pacientes bariátricos

Tabela 2: Tempo de cirurgia, características antropométricas e comportamento alimentar de mulheres com 24 meses ou mais de gastroplastia redutora em Y-de-Roux, de acordo com hábitos de vida recomendados para pacientes bariátricos

Tabela 3: Parâmetros associados à qualidade da dieta de mulheres com 24 meses ou mais de gastroplastia redutora em Y-de-Roux, de acordo com hábitos de vida recomendados para pacientes bariátricos

Tabela 4: Fatores associados aos hábitos de vida satisfatórios de mulheres com 24 meses ou mais de gastroplastia redutora em Y-de-Roux 


\section{LISTA DE ABREVIATURAS}

CNPq - Conselho Nacional de Desenvolvimento Científico e Tecnológico

DCNT - Doença Crônica Não Transmissível

DM - Diabetes Mellitus tipo 2

GRYR - Gastroplastia Redutora em Y-de-Roux

HAS - Hipertensão Arterial Sistêmica

HUB - Hospital Universitário de Brasília

IMC - Índice de Massa Corporal

NCEP - National Cholesterol Education Program

OMS - Organização Mundial de Saúde

PAPB - Pirâmide Nutricional Adaptada ao Paciente Bariátrico

PEP - Perda de Excesso de Peso

POF - Pesquisa de Orçamentos Familiares

QFCA - Questionário de Frequência do Consumo Alimentar

QFAD - Questionário de Frequência Alimentar Direcionado

R24h - Recordatório 24 horas

SBCBM - Sociedade Brasileira de Cirurgia Bariátrica e Metabólica

SPSS - Statistical Package for the Social Sciences

SUS - Sistema Único de Saúde

TACO - Tabela Brasileira de Composição de Alimentos

TFEQ-R21 - Questionário dos Três Fatores Alimentares (Three factor eating questionaire)

VIGITEL - Vigilância de Fatores de Risco e Proteção para Doenças Crônicas por Inquérito Telefônico 


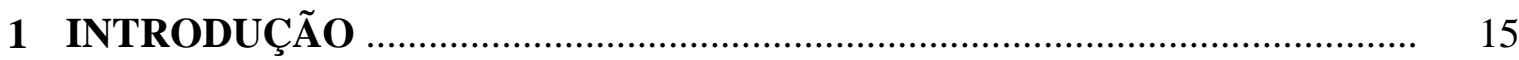

2 REVISÃO DE LITERATURA …………………….................................. 17

2.1 OBESIDADE MÓRBIDA E CIRURGIA BARIÁTRICA …………………….... 17

2.2 COMPORTAMENTO E CONSUMO ALIMENTAR RECOMENDADO NO

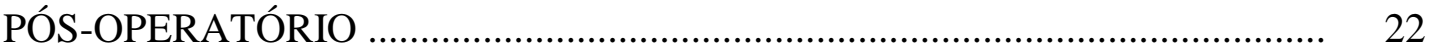

2.3 INSTRUMENTO DE AVALIAÇÃO DO CONSUMO ALIMENTAR ............... 25

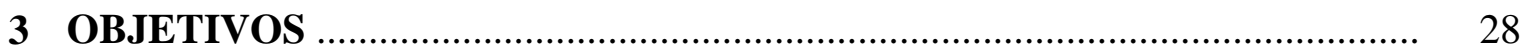

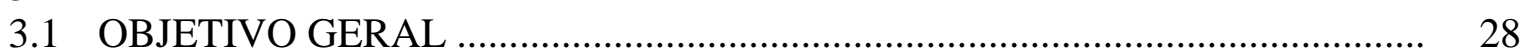

3.2 OBJETIVOS ESPECÍ́FICOS _....................................................................... 28

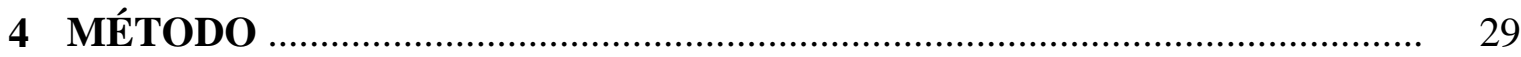

4.1 TIPO DE ESTUDO, LOCAL E AMOSTRA ………………………………... 29

4.2 CARACTERIZAÇÃO DO AMBULATÓRIO DE OBESIDADE GRAVE DO

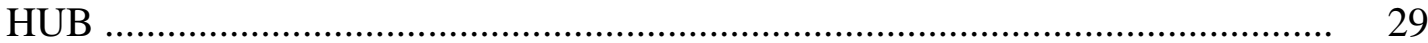

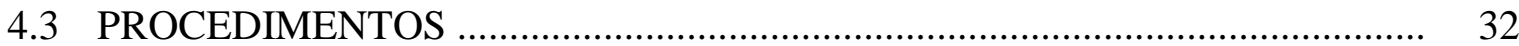

4.3.1 Coleta de dados ………………………………………………….... 32

4.3.2 Análise dos dados ............................................................................... 38

4.3.2.1 Variáveis de estudo ................................................................................. 38

5 RESUlTADOS: ARTIGO "QUALIDADE E COMPORTAMENTO ALIMENTAR DE MULHERES APÓS 24 MESES DE CIRURGIA BARIÁTRICA"

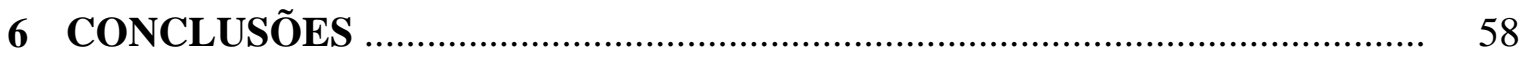

7 CONSIDERAÇÕES FINAIS ............................................................................ 59

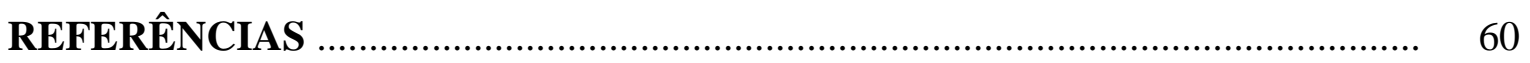

APÊNDICE A Termo de Consentimento Livre e Esclarecido ……........................ 68

APÊNDICE B Questionário de dados sociodemográficos e antropométricos ... 71

APÊNDICE C Questionário de frequência alimentar diferenciado ………….... 72

ANEXO A Aprovação no Comitê de Ética e Pesquisa ……………………….... 74

ANEXO B Questionário de Atividade Física (Vigitel) …………………….... 76

ANEXO C Questionário dos Três Fatores Alimentares (TFEQ-R21) ........... 78 


\section{INTRODUÇÃO}

A alimentação cumpre um papel fundamental na promoção e manutenção da saúde. Assim, o padrão alimentar dos indivíduos é atributo para a definição de seu estado de saúde, crescimento e desenvolvimento durante todo o curso da vida (WHO, 2004).

Internacionalmente observa-se mudanças semelhantes nos padrões alimentares, incluindo-se a redução do consumo de alimentos ricos em vitaminas, minerais e fibras e aumento do consumo de gêneros com altos teores de gordura saturada e açúcares (POPKIN; GORDON-LARSEN, 2004). Esse fenômeno foi impulsionado, principalmente, pelas mudanças no sistema mundial de alimentos, que produz e comercializa cada vez mais alimentos processados, tornando-os mais acessíveis e mais comercializados (SWINBURN et al., 2011). Aliadas a essas mudanças, a prática irregular e insuficiente de atividade física e aspectos genéticos, psicológicos, sociais, econômicos, comportamentais, culturais, entre outros, caracterizam e fundamentam a etiologia multifatorial da obesidade (LOSS et al., 2009).

Segundo a Organização Mundial da Saúde, no ano de 2008, cerca de 1,5 bilhões de adultos estavam acima do peso e destes 500 milhões eram obesos (WHO, 2011). Estima-se, ainda, que até 2015, aproximadamente, 2,3 bilhões de adultos estarão com sobrepeso e mais de 700 milhões serão obesos (WHO, 2010).

No Brasil, a Pesquisa de Orçamentos Familiares (POF) 2008-2009,constatou que, em relação aos dados anteriores, houve aumento no excesso de peso e obesidade na população adulta brasileira, ou seja, com mais de 20 anos de idade. Foi estimada uma prevalência de obesidade e de excesso de peso, respectivamente, de $12,4 \%$ e de $50,1 \%$ em homens e, de 16,9\% e 48\% entre as mulheres (IBGE, 2010).

Com relação às informações sobre a obesidade mórbida no Brasil, o estudo de Santos et al. (2010) que comparou os bancos de dados de três inquéritos antropométricos nacionais (ENDEF1974-1975, PNSN 1989 e POF 2002-2003), estimou que uma prevalência que demonstra um aumento de aumento $255 \%$ ao longo de em trinta anos, passando de 0,18\% (1974-1975) para 0,33\% (1989) e 0,64\% (2002-2003). Observou-se, também, que a prevalência da obesidade mórbida foi mais elevada na Região Sul nos dois primeiros levantamentos, sendo que a Região Sudeste apresentou aumento acelerado, superando o valor estimado para a Região Sul em 2002-2003, atingindo uma prevalência de $0,77 \%$. 
No estudo de Oliveira (2013), que comparou as prevalências entre ENDEF 1974/1975 e POF 2008/2009, foi possível verificar o rápido avanço da obesidade mórbida no país, em velocidade superior à da obesidade em geral, principalmente no sexo masculino. Enquanto a prevalência de obesidade nos homens aumentou em mais de quatro vezes (de 2,8\% para 12,4\%) neste período, a da obesidade mórbida aumentou em 11 vezes (de $0,04 \%$ para $0,44 \%$ ). Nas mulheres, a obesidade aumentou em duas vezes (de $8,0 \%$ para $16,9 \%$ ) e a obesidade mórbida em quase quatro vezes (de 0,32\% para 1,14\%). Ainda assim, a prevalência de obesidade mórbida em 2008/2009 foi 2,6 vezes mais frequente no sexo feminino do que no masculino.

O tratamento da obesidade mórbida, além da abordagem clínica e outras possíveis, encontra na cirurgia bariátrica uma importante estratégia de intervenção, sendo Gastroplastia Redutora em Y-de-Roux (GRYR) a técnica cirúrgica mais amplamente empregada (AACE/TOS/ASMBS, 2008). Apesar da magnitude do emagrecimento proporcionado por este tratamento, algum grau de reganho de peso tem sido documentado, particularmente após os 24 meses da cirurgia (HOJO; MELO; NOBRE, 2007; DALCANALE et al., 2010;). Atribui-se o reganho de peso, em parte, às modificações decorrentes do hábito alimentar no pós-operatório tardio, com maior capacidade de consumo, associada à pior qualidade dos alimentos escolhidos, resultando em elevada ingestão energética e de baixo valor nutricional (AACE/TOS/ASMBS, 2008; MAGRO et al., 2008).

A avaliação das práticas alimentares, com instrumentos direcionados, e o entendimento dos fatores que influenciam a qualidade da dieta, são relevantes para o direcionamento do aconselhamento nutricional no pós-operatório tardio de cirurgia bariátrica, ainda não consolidado pelos profissionais ou pela Academia. Visando garantir melhores resultados com a cirurgia, a curto e longo prazo, Moizé et al. (2010) propuseram um modelo de Pirâmide Nutricional Adaptada ao Paciente Bariátrico (PAPB), como instrumento de promoção de práticas de vida saudáveis para essa população.

O estudo que se apresenta teve como objetivo avaliar o consumo alimentar de mulheres com 24 meses ou mais de realização da cirurgia bariátrica, investigando os fatores associados à qualidade da dieta e utilizando a PAPB como instrumento de avaliação. 


\section{REVISÃO DE LITERATURA}

\subsection{OBESIDADE MÓRBIDA E CIRURGIA BARIÁTRICA}

A obesidade é uma Doença Crônica Não Transmissível (DCNT), de custo elevado, de etiologia multifatorial, resultado da interação de fatores ambientais, genéticos, sociais, psicológicos, comportamentais, econômicos, culturais, entre outros. Os vários fatores envolvidos no desenvolvimento da obesidade exigem uma abordagem, tanto preventiva, quanto terapêutica, complexa e também multifatorial. Atualmente, é considerada um grave problema de saúde pública, atingindo proporções epidêmicas nos países desenvolvidos e em desenvolvimento (OPAS, 2007).

O parâmetro proposto para classificação da obesidade, pela Organização Mundial de Saúde, é o Índice de Massa Corporal (IMC), bastante empregado na prática clínica. Denomina-se obesidade grau I quando a faixa de IMC está entre 30 e $34,9 \mathrm{~kg} / \mathrm{m}^{2}$, obesidade grau II na faixa entre 35 e $39,9 \mathrm{~kg} / \mathrm{m}^{2}$, obesidade grau III ou obesidade mórbida para IMC $\geq 40 \mathrm{~kg} / \mathrm{m}^{2}$ (WHO, 2000). Com o aumento da obesidade grau III, alguns estudos apresentam essa classificação dividida em superobesos quando o IMC está $\geq 50 \mathrm{~kg} / \mathrm{m}^{2}$ (MONGOL, CHOSIDOW, MARMUSE, 2005) e super-superobeso para indivíduos com IMC $\geq 60 \mathrm{~kg} / \mathrm{m}^{2}$ (THEREAUX et al., 2014). Outra forma de classificação de obesidade mórbida ou grave é apresentar $100 \%$ ou mais acima do seu peso esperado (CROOKES, 2006).

Dentre algumas doenças associadas com a presença e gravidade da obesidade, destacam-se: doenças cardíacas, acidente vascular cerebral, hipertensão arterial sistêmica (HAS), alguns tipos de câncer, doenças respiratórias crônicas e diabetes mellitus tipo 2 (DM2) (OPAS, 2007; WHO, 2008).

Para o tratamento da obesidade existe atualmente um conjunto de medidas que englobam o tratamento clínico, constituído de dieta (reeducação alimentar), prática de atividade física regular, assistência psicológica e medicamentos, que nem sempre se traduzem em resultados eficazes. No caso de obesidade grave, além do tratamento clínico, procedimentos cirúrgicos têm sido cada vez mais empregados, apesar de também apresentarem suas limitações, de curto ou longo prazo.

Indica-se este tratamento nos casos de IMC superior ou igual a $40 \mathrm{~kg} / \mathrm{m}^{2}$ ou superior a $35 \mathrm{~kg} / \mathrm{m}^{2}$ associado a, pelo menos, uma comorbidade (como doenças 
cardiopulmonares, DM2, HAS e artropatias). Além disso, o candidato deverá apresentar histórico de falência do tratamento convencional (dietoterapêuticos, psicoterapêuticos, medicamentosos, exercícios físicos) realizado por profissionais qualificados, continuamente, há pelo menos dois anos. O tratamento não é indicado nos casos de dependência de drogas ilícitas ou alcoolismos, quadros psicóticos ou demências graves ou moderadas, além de condições físico-clínicas que contraindiquem cirurgias de grande porte (cirrose hepática, cardiopatias, pneumopatias, insuficiência renal crônica e outras). Presença de depressão, transtornos alimentares, perda insuficiente de peso no préoperatório e baixa adesão ao tratamento não são contraindicações formais para cirurgia bariátrica. Contudo, o paciente deverá ser capaz de se cuidar ou dispor de pessoas ou instituições que garantam seu acompanhamento pós-operatório adequado com equipe multidisciplinar, por toda a vida (BRASIL, 2001; AACE/TOS/ASMBS, 2008).

A cirurgia bariátrica é procedimento de alta complexidade realizada pelo Sistema Único de Saúde (SUS). Em 2011, havia no SUS 78 estabelecimentos habilitados em 20 estados para prestar assistência à saúde de alta complexidade aos pacientes com obesidade mórbida (BRASIL, 2012). No ano de 2007, esse tratamento encontrava-se disponível em 53 centros nacionais de referência em cirurgia bariátrica, segundo a Portaria GM/MS n ${ }^{\circ}$ 628, de 26 de abril de 2001, atualizada em 29 de junho de 2007, sendo, em sua maioria, hospitais universitários (BRASIL, 2007).

O Ministério da Saúde instituiu, em 2013, a linha de cuidados prioritários do sobrepeso e da obesidade na rede de atenção às pessoas com doenças crônicas no SUS. Nela, o cuidado é definido desde a orientação e apoio à mudança de hábitos até os critérios rigorosos para a realização da cirurgia bariátrica, último recurso para atingir a perda de peso (BRASIL, 2013).

A cirurgia bariátrica pode ser dividida em três tipos: restritivas, disabsortivas e mistas (Figura 1). As técnicas puramente restritivas são caracterizadas pela redução da capacidade gástrica, levando à menor ingestão energética. São a gastrectomia vertical (Sleeve), gastroplastia vertical com banda gástrica e banda gástrica ajustável. As predominantemente disabsortivas, que incluem a derivação biliopancreática (Scorpinaro) e duodenal Switch, resultam em restrição energética e redução no trânsito intestinal com limitação importante da absorção de nutrientes. A técnica mista associa o componente restritivo ao disabsortivo, ocasionando menor ingestão energética e redução na absorção de nutrientes, sendo a mais conhecida a Gastroplastia Redutora em Y-de-Roux (GRYR). Enquanto as técnicas puramente restritivas podem resultar em perda de peso insatisfatória, 
as técnicas predominantemente disabsortivas são raramente realizadas em decorrência do seu alto índice de complicações (AACE/TOS/ASMBS, 2008). Por sua vez, a GRYR é a mais empregada nos Estados Unidos e no Brasil, sendo a mais recomendada pela Sociedade Brasileira de Cirurgia Bariátrica e Metabólica (SBCBM) por proporcionar os melhores resultados (GARRIDO JR, 2006; AACE/TOS/ASMBS, 2008).

Figura 1: Principais tipos de cirurgia bariátrica

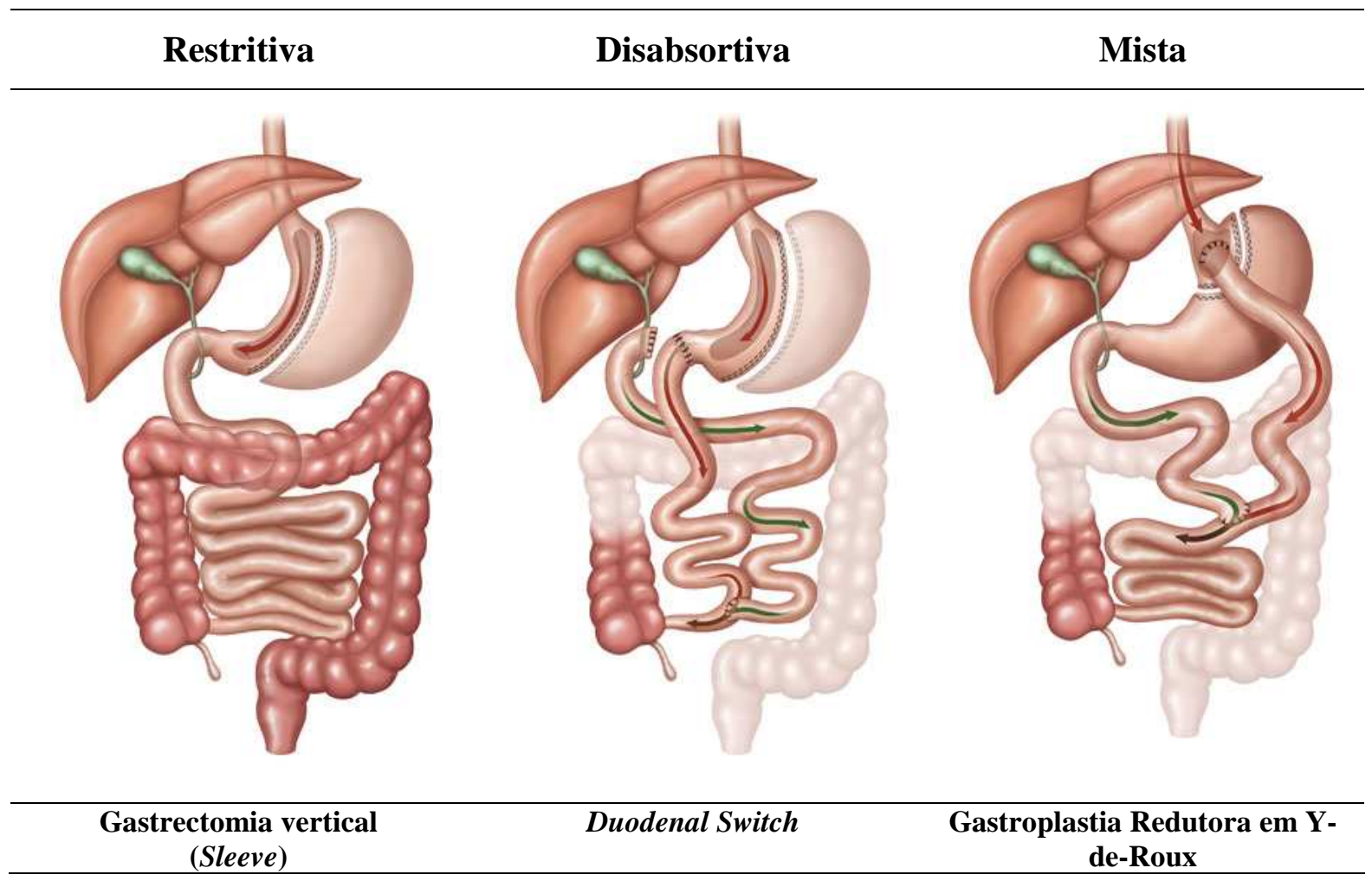

Adaptado de: SBCBM, 2014.

A GRYR apresenta resultados mais consistentes em longo prazo, como uma perda média de excesso de peso corporal de $60-75 \%$, sendo maior no primeiro ano de pósoperatório (SILVER et al., 2006). Após este período, a taxa de emagrecimento torna-se menor e normalmente ocorre estabilização após 18 a 24 meses (SJÖSTRÖM; LINDROOS; PELTONEN, 2004). A técnica consiste na criação de uma secção gástrica com formação de pequeno reservatório com capacidade em torno de $30 \mathrm{ml}$ na curvatura baixa do estômago, o qual é separado do restante do órgão por grampeamento (AACE/TOS/ASMBS, 2008). O intestino delgado é colocado na forma de Y-de-Roux, com a alça alimentar medindo cerca de 100 a $150 \mathrm{~cm}$, a qual é anastomosada com a bolsa gástrica. Em algumas cirurgias é colocado ainda um anel em torno da bolsa gástrica para prevenir que ela se dilate ao longo do tempo (EVANGELISTA; CAMPOS, 2011). 
Para avaliação dos resultados, a perda de peso obtida é o principal parâmetro utilizado para sucesso da cirurgia, principalmente quando associada à melhora ou remissão de comorbidades (AACE/TOS/ASMBS, 2008). A avaliação da perda ponderal é usualmente feita pelo percentual da perda de excesso de peso (\%PEP), sendo estabelecida como sucesso a redução de no mínimo $50 \%$ do excesso de peso (GUERRA; JIMÉNEZ, 2002; GARRIDO JR, 2006).

Outro parâmetro utilizado é o IMC pós-operatório, em que são considerados adequados valores inferiores a $35 \mathrm{~kg} / \mathrm{m}^{2}$ para indivíduos com IMC pré-operatório menor que $50 \mathrm{~kg} / \mathrm{m}^{2}$. No caso de indivíduos superobesos, espera que seja atingido IMC inferior a 40 kg/m² no pós-operatório (GARRIDO JR, 2006; AACE/TOS/ASMBS, 2008).

A cirurgia tem resultados eficientes na perda de peso e na qualidade de vida do obeso mórbido, entretanto algumas complicações podem ocorrer no pós-operatório, como a intolerância a determinados alimentos, síndrome de dumping, alterações gastrointestinais e deficiência nutricionais. Além do risco nutricional, o reganho de peso também é uma das limitações da cirurgia (HOJO; MELO; NOBRE, 2007).

No primeiro ano de cirurgia, a perda de peso ocorre de maneira acelerada, com redução do ritmo após esse período (SJÖSTRÖM; LINDROOS; PELTONEN, 2004; SILVER et al., 2006). A redução da gordura corporal, especialmente a visceral, é associada a melhoras metabólicas, como aumento da sensibilidade à insulina, melhor captação de glicose, menor fluxo de ácidos graxos livres, redução de citocinas pró-inflamatórias e redução dos níveis de pressão arterial (AACE/TOS/ASMBS, 2008).

A metanálise conduzida por Buchwald et al. (2004) mostrou que entre os 989 sujeitos submetidos à GRYR e considerados no estudo, 83,7\% tiveram o quadro de diabetes tipo 2 resolvida após 2 anos de cirurgia e cerca de $78 \%$ apresentaram melhora dos quadros de HAS e dislipidemias, reduzindo o risco associado a eventos cardiovasculares.

Freire et al. (2012), estudando 100 pacientes submetidos à GRYR, verificaram que $97 \%$ dos pacientes tinham, pelo menos, uma das quatro comorbidades associadas à obesidade consideradas: HAS, DM, hiperlipidemia e apnéia obstrutiva do sono. Após cirurgia, o número de pacientes com, pelo menos, uma comorbidade reduziu para $64 \%$. Observou-se, também, que a presença de um reganho de peso superior a $10 \%$ em relação ao menor peso pós-operatório está associado à maior prevalência de comorbidade nesses pacientes.

No Brasil, Silva-Neto et al. (2014) em um estudo transversal realizado em Sergipe no qual avaliaram e quantificaram a evolução clínica de pacientes submetidos à GRYR, 
verificaram que houve redução significativa do escore médio de todas as comorbidades associadas à obesidade, como DM2, dislipidemia e HAS, tanto desde a admissão,quanto na liberação para a operação e também nos retornos do pós-operatório (três, seis e 12 meses) até os 12 meses de pós-operatório. No mesmo sentido, Monteiro Júnior et al. (2009) observaram que a síndrome metabólica foi uma ocorrência comum em obesos candidatos à cirurgia bariátrica e esse procedimento mostrou-se eficaz na regressão da síndrome. Foi verificada redução da prevalência em todos os critérios avaliados de acordo com o protocolo apresentado e aplicado pelo Programa Nacional de Educação em Colesterol, dos Estados Unidos (National Cholesterol Education Program - NCEP).

No estudo realizado por Pedrosa et al. (2009), em Pernambuco, sobre o perfil clínico-nutricional de pacientes obesos submetidos à cirurgia bariátrica, evidenciou-se síndrome metabólica em 26,8\% no pré-operatório e DM2 e HAS, em 11,7\% e 52,7\%, respectivamente. No $6^{\circ}$ mês pós-operatório, apenas $2 \%$ permaneceram com HAS, ocorrendo remissão em 100\% dos casos de DM2. A avaliação dos períodos pós-operatórios demonstrou redução gradativa do peso e IMC, com diferença estatística em todas as fases, atingindo com 18-24 meses o menor peso e IMC e maior Percentual de Perda de Excesso de Peso (\%PEP).

Em alguma medida, a melhora das comorbidades observada após a cirurgia bariátrica independe da perda ponderal pós-operatória. Esta constatação gerou o conceito de cirurgia metabólica (SCHERNTHANER et al., 2011; CUMMINGS, 2012; CAMPOS et al., 2013). De todas as doenças associadas à obesidade, aquela que melhor apresenta controle após cirurgia é o DM2. Sá et al. (2011) analisaram pacientes diabéticos descontrolados submetidos à GRYR, durante um período médio de 20 meses, e evidenciaram que $74 \%$ descontinuaram o uso de hipoglicemiantes, dos quais $20 \%$ alcançaram a remissão do DM2. Di Giorgi et al. (2010) encontraram situação semelhante, em um estudo retrospectivo com pacientes em pós-operatório durante três anos de seguimento. Foi observado, nos primeiros seis meses de pós-operação, que todos tiveram melhora do DM2, com 64\% atingindo resolução completa.

A eficiência do tratamento cirúrgico, contudo, depende de sistemático acompanhamento não apenas no pré-operatório, mas após o procedimento, seja a curto ou longo prazo (CRUZ; MORIMOTO, 2004; PEDROSA et al., 2009; HEBER et al., 2010). Em cada momento, a abordagem deve ser multidisciplinar, seja para avaliar aspectos comportamentais, clínicos ou bioquímicos. Ao longo dos anos espera-se boa adesão a um estilo de vida saudável, para garantir perdas ponderais significativas e sustentáveis, com 
consequente melhora das comorbidades e da qualidade de vida (MONTEIRO JÚNIOR et al., 2009; GUEDES et al., 2009; COSTA et al., 2010).

Este cuidado é fundamental e pode evitar o reganho de peso, comum a partir dos 24 meses de pós-operatório (CHRISTOU; EFTIMIOU, 2009; ODOM et al., 2010). Ainda não está bem determinado a partir de qual percentual sua ocorrência deve ser considerada significativa, com piora de comorbidades anteriormente controladas. Com o passar dos anos de cirurgia, adaptações físicas relacionadas ao procedimento cirúrgico e modificações comportamentais podem ocorrer de maneira desfavorável à manutenção ponderal pósoperatória.

Nesta conjuntura, alguns estudos identificaram a relevância do tempo de cirurgia no reganho de peso pós-operatório. Barham et al. (2011), ao avaliarem 165 pacientes submetidos à GRYR (4,6 $\pm 3,0$ anos), demonstraram que o tempo de cirurgia foi positivamente associado ao reganho de peso pós-operatório. Os dados são corroborados por Magro et al. (2008) e Freire et al. (2012), que identificaram aumento da prevalência de reganho ponderal em indivíduos com maior tempo de pós-operatório.

O tempo de cirurgia e especialmente o comportamento alimentar parecem ser elementos chaves que determinam o resultado do tratamento. Daí a necessidade de avaliação e acompanhamento destes pacientes, não apenas no pós-operatório de curto prazo, mas de forma sistemática ao longo de sua vida, visando controle dessa situação, considerada crônica.

\subsection{COMPORTAMENTO E CONSUMO ALIMENTAR RECOMENDADO NO PÓS- OPERATÓRIO}

Strunkard e Messick (1985) sugerem três dimensões do comportamento alimentar a serem avaliados, de forma geral: a restrição cognitiva, o descontrole alimentar e a alimentação emocional. Para avaliá-las propõem oo questionário de três fatores alimentares (TFEQ) que, incialmente, foi elaborado com 51 questões. Com o objetivo de facilitar sua aplicabilidade, foi reduzido a 21 questões (TFEQ-21) por Tholin. et al. (2005).

A restrição cognitiva é caracterizada por um conjunto de obrigações e proibições alimentares para manter ou perder peso. A alimentação emocional é a susceptibilidade do indivíduo em apresentar modificações na ingestão alimentar decorrente de alterações do humor ou situações desafiadoras, ou seja, uma propensão maior ao consumo alimentar em 
resposta a estados emocionais negativos. O descontrole alimentar, por sua vez, é a perda do autocontrole e consumo exagerado de alimentos, com ou sem a presença de fome. Estes comportamentos não são isolados, uma vez que o indivíduo pode apresentar características de todos eles, simultaneamente. Os autores inferem que o indivíduo que apresenta comportamento exacerbado de restrição alimentar apresenta também o descontrole alimentar em situações diversas e até a alimentação emocional, aumentando a ingestão de alimentos em momentos de estresse (THOLIN et al., 2005). A presença exacerbada de um ou mais desses comportamentos está associado á ocorrência de distúrbios alimentares (NATACCI; FERREIRA JUNIOR, 2011).

É sugerido que o componente restritivo da GRYR poderia favorecer o comportamento alimentar (SARWER et al., 2008), levando ao aumento de comportamentos de restrição cognitiva e diminuindo os de descontrole alimentar (COLLES et al., 2008; SARWER et al., 2008). Niego et al. (2007) concluíram que os maiores beneficiados com a diminuição da capacidade gástrica seriam os consumidores de grandes quantidades de alimentos, concentradas em poucas refeições. Já os beliscadores não teriam os mesmos benefícios, pois consomem pequenas porções de alimentos em vários momentos, o que não seria modificado com a realização da cirurgia. Colles et al. (2008) observaram aumento na prevalência de beliscadores de $26 \%$ para $38 \%$ após 12 meses de cirurgia e Kofman et al. (2010) identificaram que $46 \%$ dos pacientes com 3 a 10 anos de cirurgia relataram continuar beliscando.

A presença do comportamento de beliscar pode levar à maior ingestão energética, com possíveis prejuízos na perda ponderal (COLLES et al., 2008). Ademais, a incapacidade de consumir grandes porções de alimentos pode desencadear a transferência ou substituição de um quadro de compulsão alimentar no pós-operatório por um novo comportamento compulsivo, como o uso de drogas, o uso abusivo de bebidas alcoólicas, compulsão por compras ou jogos de azar (MCFADDEN, 2010).

As orientações dietéticas disponíveis para os pacientes de cirurgia bariátrica geralmente estão baseadas em progressão das fases alimentares, do período de pósoperatório imediato até seis meses após a cirurgia. No entanto, as orientações alimentares de longo prazo para aqueles tratados cirurgicamente não estão facilmente disponíveis (MOIZÉ et al., 2010).

O consumo alimentar no pós-operatório deve seguir um padrão alimentar saudável, com o consumo de todos os grupos alimentares, a fim de evitar o desenvolvimento de carências nutricionais e a desnutrição e também favorecer a perda de 
peso adequada e evitar o reganho ponderal. Mas, o consumo alimentar pode ser afetado pelas alterações anatômicas e fisiológicas no trato gastrointestinal, como menor área de absorção, a diminuição da tolerância alimentar e consequente aversão a alimentos específicos, síndrome de dumping, entre outros complicações. A ingestão, principalmente de energia, proteínas, vitaminas e minerais, em alguns pacientes, pode ser inferior a $50 \%$ das suas necessidades nutricionais (PREVEDELLO et al., 2009).

Durante os primeiros 6 meses após a cirurgia, geralmente o consumo fica entre 900 a $1.000 \mathrm{kcal}$ com aumento gradual ao longo do tempo (O’DONNELL, 2004). Isso foi também observado por Silva et al. (2005), em Pernambuco, Brasil, no qual o consumo energético médio reduziu para $1.063 \mathrm{kcal}$ nos pacientes com período inferior a 6 meses de pós-operatório, aumentando para $1.115 \mathrm{kcal}$ entre 6 e 11 meses e 1.194 kcal 12 a 24 meses. O consumo de proteína seguiu a mesma proporção, aumentando de 55,7 gramas no período inferior a seis meses para 64 gramas entre 12 e 24 meses após a cirurgia.

Em adultos saudáveis, não bariátricos, a recomendação diária para ingestão de proteína na dieta é de $0,8 \mathrm{~g} / \mathrm{kg} /$ dia. Para pacientes que foram submetidos à gastroplastia, a ingestão de proteína deve ser de 60 a 80 gramas por dia ou de 1 a 1,5 gramas por $\mathrm{kg}$ de peso ideal por dia (RAFTOPOULOS et al., 2011). O' Donnell (2004) encoraja o consumo de pelo menos 50 a $60 \mathrm{~g}$ de proteína por dia, sendo que dieta com alto teor de proteínas visa auxiliar a perda de peso, promover saciedade, favorecer a termogênese e auxiliar na manutenção da massa magra (PADDON-JONES et al., 2008). Entretanto, o procedimento cirúrgico diminui a área funcional do estômago, reduzindo a disponibilidade de pepsina, renina e ácido clorídico, o que dificulta a digestão proteica. Moizé et al. (2003) concluíram que, após a cirurgia, o consumo de proteínas tende a ser insuficiente, sendo mediado possivelmente por intolerância às fontes proteicas.

Na ausência de melhor evidência, propõe-se manter a ingestão de gordura no pósoperatório na faixa inferior a $30 \%$ das calorias diárias. Deve ser observada não só a quantidade, mas também a qualidade de gordura consumida. Óleo de peixe, azeite de oliva, óleo de soja, girassol, canola e linhaça são boas opções (MOIZÉ et al., 2010).

Não há recomendações específicas sobre a ingestão de carboidratos em diretrizes recentes para o suporte nutricional do paciente bariátrico. Faria et al. (2009), em estudo com 89 pacientes submetidos à GRYR, observaram que o aumento do consumo de carboidratos aumenta a carga glicêmica da dieta e diminui a perda ponderal mensal. Moizé et al. (2010) recomendam 40-45\% da energia diária provenientes de carboidratos e uma 
ingestão de fibra alimentar de, cerca de, 14 gramas/mil calorias para o paciente em pósoperatório tardio.

A dieta deve ser fracionada em cinco a seis refeições por dia, considerando que, muitas vezes, o paciente não é capaz de suprir suas necessidades em poucas refeições. Além disso, a mastigação deve ser enfatizada, visto que uma mastigação ineficiente pode favorecer episódios eméticos, em decorrência da menor capacidade gástrica, e prejudicar a absorção de nutrientes (SHAH; SIMHA; GARG, 2006). No entanto, especula-se se o fracionamento da dieta poderia prejudicar a perda ponderal, por aumentar o consumo energético (RIBEIRO et al., 2006).

Quanto ao consumo de água, com a redução da capacidade gástrica, alguns pacientes apresentam dificuldade em ingerir grandes quantidades de líquidos, devendo ser incentivados a aumentar a frequência da ingestão de água ao longo do dia (MARCASON, 2004). A desidratação pode ser um problema de saúde em pacientes de pós-operatório e a limitação no consumo hídrico pode favorecer o desenvolvimento de cálculos biliares (TUCKER; SZOMSTEIN; ROSENTHAL, 2007).

A suplementação de vitaminas e minerais é faz parte do protocolo de tratamento e na maioria das vezes deve ser avaliada individualmente (BORDALO et al., 2011). A suplementação de micronutrientes no período pós-operatório é fundamental para evitar as possíveis deficiências nutricionais, das quais o paciente bariátrico está susceptível (REBOLLEDO et al., 2009).

Cruz e Morimoto (2004) enfatizam a importância da elaboração de um protocolo de atendimento para estabelecimento de diretrizes de conduta nutricional eficazes no pósoperatório tardio. O monitoramento destes pacientes exige a necessidade de instrumentos viáveis e específicos para avaliação do consumo alimentar.

\subsection{INSTRUMENTOS DE AVALIAÇÃO DO CONSUMO ALIMENTAR: QUESTIONÁRIO DE FREQUÊNCIA DO CONSUMO ALIMENTAR (QFCA)}

O consumo de alimentos acompanha o ser humano ao longo de toda a sua existência e, por definição, representa ações que estão intimamente relacionadas aos aspectos culturais, geográficos, antropológicos, socioeconômicos, religiosos, neurofisiológicos e psicológicos que envolvem o ambiente das pessoas e que contribui para o seu estado de saúde ou doença (TORAL; SLATER, 2007). A avaliação da dieta, seja de 
forma qualitativa ou quantitativa, possibilita investigar associação do padrão alimentar e sua associação com doenças, além de fundamentar as recomendações nutricionais para diferentes grupos populacionais, de acordo com suas necessidades (FISBERG et al., 2005).

Considerando a complexidade dos determinantes da alimentação cotidiana, conhecer o consumo alimentar dos indivíduos é uma atividade complexa, que requer o conhecimento de métodos adequados para quantificação e interpretação dos resultados obtidos. Os métodos mais utilizados para obtenção de informações sobre o consumo alimentar individual e de grupos populacionais são: diário ou registro alimentar, o recordatório 24 horas $(\mathrm{R} 24 \mathrm{~h})$ e o questionário de frequência do consumo alimentar (QFCA) que foi o instrumento selecionado para o presente estudo. No caso do obeso em particular, são várias as limitações da aplicação destes inquéritos, seja pela dificuldade de adesão, subrelatos, falta de padrões quanto aos pesos e medidas, entre outras dificuldades metodológicas (BOHM; GIMENES, 2008; GOMES; LEÃO, 2011; AVELINO et al., 2014).

O QFCA é um método de avaliação do consumo alimentar adequado para investigar a associação entre o consumo dietético e a ocorrência de DCNT, amplamente utilizado em estudos epidemiológicos e usado para estimar o consumo usual ao longo de determinado período (FISBERG et al., 2005). O QFCA possui basicamente dois componentes: uma lista de alimentos e um espaço, no qual o indivíduo responderá com que frequência consome cada alimento. A lista deve conter alimentos fontes dos nutrientes de interesse. A análise do QFCA pode ser interpretada de acordo com algum padrão de referência de consumo, como o número de porções de frutas e hortaliças, assim como de outros grupos alimentares, que devem ser ingeridas diariamente (FISBERG et al., 2005; KAC et al., 2007). Há três tipos de QFCA: o qualitativo, pelo qual se obtém informações sobre os alimentos consumidos, sem incluir dados de quantidades; o quantitativo, onde é incluída uma questão aberta para estimar a quantidade ou uma porção média usualmente consumida; o semiquantitativo, que inclui uma porção de referência para que o respondente estime o consumo habitual (PEREIRA; SICHIERI, 2007). São consideradas vantagens: a simplicidade do método, o baixo custo, a logística da coleta de dados e a possibilidade de distinção dos diferentes padrões de consumo entre os indivíduos (SLATER et al., 2003). As principais limitações são decorrentes da estimativa das porções e da limitação dos alimentos listados (BROWNELL et al., 2006). Slater e Lima (2005) assinalam que a baixa precisão na estimativa das porções consumidas pode comprometer a validade do QFCA. 
No estudo de Freire et al. (2012), realizado em Minas Gerais, com 100 pacientes de ambos os sexos submetidos à GRYR, o consumo alimentar foi avaliado através do QFCA composto por 85 itens, mostrando uma ingestão insuficiente de alimentos de boa qualidade, como frutas, hortaliças, carnes e ovos, laticínios, feijão e carboidratos, e uma ingestão maior de doces e lanches, que são alimentos que têm seu consumo limitado.

Estimativa de consumo alimentar tem demonstrado uma alta prevalência de subrelato em indivíduos avaliados em nível ambulatorial, sendo maior em sujeitos com excesso de peso (GOMES; LEÃO, 2011; AVELINO et al., 2014). Portanto, parece que o subrelato está associado à obesidade e à percepção dos avaliados da necessidade de restrição energética e desejo de ajuste social. Além disso, a busca pelo reforço de aprovação do nutricionista poderia ter modelado o relato de acordo com o entendimento do que seria esperado por este profissional (WULFERT et al., 1994). Esta limitação é inerente aos métodos de avaliação do consumo alimentar (SCAGLIUSI; LANCHA JUNIOR, 2003).

É neste contexto que se apresenta este estudo: reconhece a complexidade do tratamento da obesidade grave e a necessidade de um acompanhamento a longo prazo para promoção de hábitos de vida saudáveis, visando emagrecimento sustentável, controle das comorbidades e garantia da qualidade de vida desses pacientes. A avaliação da qualidade e do comportamento alimentar surge como uma importante ferramenta para acompanhamento nutricional e comportamental de longo prazo dos pacientes bariátricos. 


\section{OBJETIVOS}

\subsection{OBJETIVO GERAL}

Avaliar o consumo alimentar de mulheres com 24 meses ou mais de realização da cirurgia bariátrica e investigar fatores associados aos hábitos de vida à qualidade da dieta.

\subsection{OBJETIVOS ESPECÍFICOS}

- Caracterizar o consumo alimentar da população de estudo, em termos quantitativos e qualitativos, de acordo com o modelo de pirâmide nutricional específica para a população bariátrica;

- Avaliar dimensões do comportamento do consumo alimentar;

- Investigar fatores sociodemográficos, clínicos e comportamentais associados à adesão de hábitos de vida recomendados para pacientes bariátricos. 


\section{MÉTODO}

O presente estudo foi aprovado no Comitê de Ética e Pesquisa da Fundação de Ensino e Pesquisa em Ciências da Saúde/Secretaria de Estado de Saúde do Distrito Federal (FEPECS), como emenda do projeto cujo protocolo é 284.638, de 27 de maio de 2013 (Anexo A). A participação dos indivíduos da pesquisa foi condicionada à assinatura do termo de consentimento livre e esclarecido (Apêndice A).

Esta pesquisa foi parcialmente financiada pelo $\mathrm{CNPq}$, no valor de $\mathrm{R} \$ 11.590,00$, por meio do edital/chamada universal 14/2011, Processo n 476459/2011-7.

\subsection{TIPO DE ESTUDO, LOCAL E AMOSTRA}

Trata-se de estudo transversal realizado no ambulatório de obesidade grave do Hospital Universitário de Brasília (HUB). Foram convidadas a participar da pesquisa mulheres submetidas à cirurgia bariátrica há pelo menos 24 meses.. Optou-se por incluir apenas mulheres, uma vez que elas representam a maior parte dos pacientes atendidos por este tipo de serviço disponível pelo SUS, e os homens, que podem apresentar práticas alimentares específicas, estariam sub-representados. Das 125 pacientes elegíveis, 95 foram localizadas e concordaram em participar da pesquisa. A coleta ocorreu entre os meses de junho a dezembro de 2013.

\subsection{CARACTERIZAÇÃO DO AMBULATÓRIO DE OBESIDADE GRAVE DO HUB}

O ambulatório de obesidade grave do HUB teve início em 2004 e é composto pelos ambulatórios especializados de Cirurgia Geral e Plástica, Endocrinologia, Nutrição, Psicologia e Serviço Social. Trata-se, assim, de serviço multidisciplinar dirigido ao obeso grave, que visa prestar assistência pré e pós-operatória aos pacientes que necessitam de cirurgia bariátrica. A indicação da cirurgia segue as diretrizes para a atenção ao paciente com obesidade grave, instituída pelo Ministério da Saúde (BRASIL, 2007; BRASIL, 2013). 
Neste programa, a equipe multiprofissional e pacientes discutem questões referentes ao procedimento cirúrgico e seus riscos, às expectativas de perda de peso e às mudanças de hábitos de vida, para que sejam alcançados melhores resultados com o tratamento.

\section{Assistência pré-operatória}

São inscritos neste programa indivíduos que apresentem Índice de Massa Corporal (IMC) superior a $40 \mathrm{~kg} / \mathrm{m}^{2}$ ou $35 \mathrm{~kg} / \mathrm{m}^{2}$ com comorbidades. São formados grupos de até 12 pacientes, na medida em que as vagas do serviço são disponibilizadas e por ordem de cadastro. Após a formação dos grupos, os pacientes passam por uma avaliação por cada equipe do serviço, para preparo e aprovação para cirurgia. No pré-operatório são realizados atendimentos em grupo, sendo semanal na psicologia e mensal com equipe da nutrição e da endocrinologia.

No acompanhamento nutricional pré-operatório, os pacientes são orientados sobre vários aspectos relacionados ao tratamento cirúrgico da obesidade, entre os quais: importância da manutenção de hábitos alimentares saudáveis; possíveis intercorrências do pós-operatório, como deficiências nutricionais, alterações gastrointestinais, intolerâncias alimentares e; sobre o risco de reganho de peso, no caso de baixa adesão ao tratamento. Prescreve-se, neste período, dieta hipoenergética de aproximadamente $16 \mathrm{kcal} / \mathrm{kg}$ de peso apresentado, com objetivo de perda de $5 \%$ a $10 \%$ do peso corporal, antes do procedimento cirúrgico. Embora o emagrecimento pré-operatório seja fortemente recomendado, visando à redução dos riscos intraoperatórios, a ausência de perda ponderal não é proibitiva para a cirurgia bariátrica.

Para avaliar o momento da indicação da cirurgia, depois do início do preparo, são considerados a realização e resultados dos exames bioquímicos, de imagem, endoscopia digestiva e polissonografia, avaliação de riscos e adesão ao tratamento. No aspecto nutricional, são parâmetros considerados:

- assiduidade às consultas pré-operatórias na nutrição;

- perda ponderal de no mínimo $3 \%$ do peso inicial;

- conhecimento da dieta prescrita e sobre alimentação saudável;

- adequação dos hábitos alimentares (avaliados pelo consumo suficiente de frutas, hortaliças e consumo raro de doces e frituras);

— frequência de prática de atividade física no lazer, de no mínimo 150 minutos semanais. 
O acompanhamento psicológico pré-operatório tem como objetivo o desenvolvimento de estratégias para lidar com o processo de mudança de estilo de vida, por meio de terapia comportamental cognitiva e técnicas de automonitoramento. Por sua vez, a equipe de endocrinologia é responsável pelo acompanhamento clínico pré-operatório e realiza a identificação e tratamento de comorbidades e tratamento farmacológico para obesidade.

\section{Assistência pós-operatória}

No pós-operatório, os pacientes são orientados a manter acompanhamento com todas as equipes. As consultas nutricionais após a cirurgia ocorrem no $15^{\circ}$ dia, $1^{\circ}, 2^{\circ}, 3^{\circ}, 6^{\circ}$, $9^{\circ}, 12^{\circ}, 18^{\circ}, 24^{\circ}$ mês e, posteriormente, uma vez ao ano; essa frequência pode ser mudada de acordo com a necessidade de acompanhamento pelo paciente. Nessas consultas são avaliados a qualidade e quantidade da dieta, magnitude da perda ponderal, presença de intercorrências pós-operatórias, como sintomas gastrointestinal e intolerâncias alimentares, além da avaliação bioquímica, sinais clínicos de deficiências nutricionais, uso de suplementação e prática de atividade física.

O acompanhamento psicológico é realizado em encontros mensais em grupo nos quais são abordadas questões referentes às dificuldades na manutenção de estilo saudável, na ocorrência de intolerâncias alimentares, autoimagem e avaliação para verificação de presença de transtornos alimentares; de acordo com a necessidade, as consultas podem ser individualizadas e com maior frequência.

Com a equipe de endocrinologia são avaliados a evolução das comorbidades, exames bioquímicos, necessidade de alterações da prescrição medicamentosa, manejo de possíveis intercorrências pós-operatórias e acompanhamento da perda ponderal. Em caso de intercorrências não associadas a aspectos clínicos, nutricionais ou psicológicos, como hérnias e obstruções digestivas, os pacientes são encaminhados à equipe de cirurgia geral para avaliação.

Após a estabilização do peso corporal, os pacientes são encaminhados para cirurgia plástica restauradora de dermolipectomia em abdômen, mamas, membros superiores e inferiores, conforme necessidade e disponibilidade do serviço, sem que esteja estabelecido um cronograma prévio para realização dos novos tempos cirúrgicos. 


\subsection{PROCEDIMENTOS}

\subsubsection{Coleta de dados}

A aplicação do questionário estruturado e o processo de avaliação nutricional foram realizados por duas pesquisadoras do Programa de Pós Graduação em Nutrição Humana pós-graduação. A equipe contou com o auxílio de uma estudante de graduação em Nutrição, que participou na captação das pacientes, agendamento das entrevistas e leitura dos prontuários. A coleta ocorreu entre os meses de junho a dezembro de 2013 e o tempo médio para a realização da entrevista e antropometria foi de 30 minutos. As seguintes informações foram coletadas no protocolo de pesquisa (Apêndices B e C):

(a) Dados sociodemográficos: questionário com questões fechadas e abertas sobre idade (anos completos), estado civil, escolaridade e renda média per capita.

(b) Data da cirurgia: para cálculo do tempo de pós-operatório.

(c) Uso de suplementos: uso contínuo ou não de polivitamínico e minerais, vitamina D, vitamina B12, cálcio e ferro, conforme prescrição.

(d) Avaliação antropométrica: o peso atual foi aferido em balança digital marca Welmy, com capacidade de $300 \mathrm{~kg}$ e precisão de 50 gramas. Para a medida, foi solicitado que as pacientes ficassem descalças e com o mínimo de roupa possível. A estatura foi aferida por estadiômetro acoplado a esta mesma balança digital, com comprimento máximo de 2,0 metros e escala de $0,5 \mathrm{~cm}$, com a participante em posição ereta com os braços relaxados ao lado do corpo, pés unidos e olhar direcionado ao horizonte. O peso no início do tratamento, no pré e pós-cirúrgico, e o menor peso alcançado após a cirurgia foram coletados das informações presentes nos prontuários (Apêndice B).

(e) Pirâmide nutricional recomendada para pacientes bariátricos (Figura 2): para avaliação do consumo alimentar, foi elaborado um questionário de frequência alimentar direcionado (QFAD) relativo aos parâmetros da PAPB proposta por Moizé et al. (2010), tradução livre, utilizando como modelo de QFCA proposto por Ribeiro et al. (2006), que foi aplicado neste inquérito. Esse modelo apresenta um formato vertical, com os alimentos ordenados em quatro grupos alimentares de acordo com o nível da pirâmide, que será detalhado a seguir, e as frequências categorizadas por: alimento consumido raro ou nunca, 1 a 3 vezes no mês, 1 vez na semana, 2 a 4 vezes na semana, 5 a 6 vezes na semana, 1 vez ao dia, 2 ou mais vezes na semana. A escolha desse formato constitui uma estratégia para 
evitar super-relato do consumo usualmente observado em QFCA, de acordo com Cade et al. (2002).

Figura 2: Pirâmide nutricional adaptada para cirurgia bariátrica

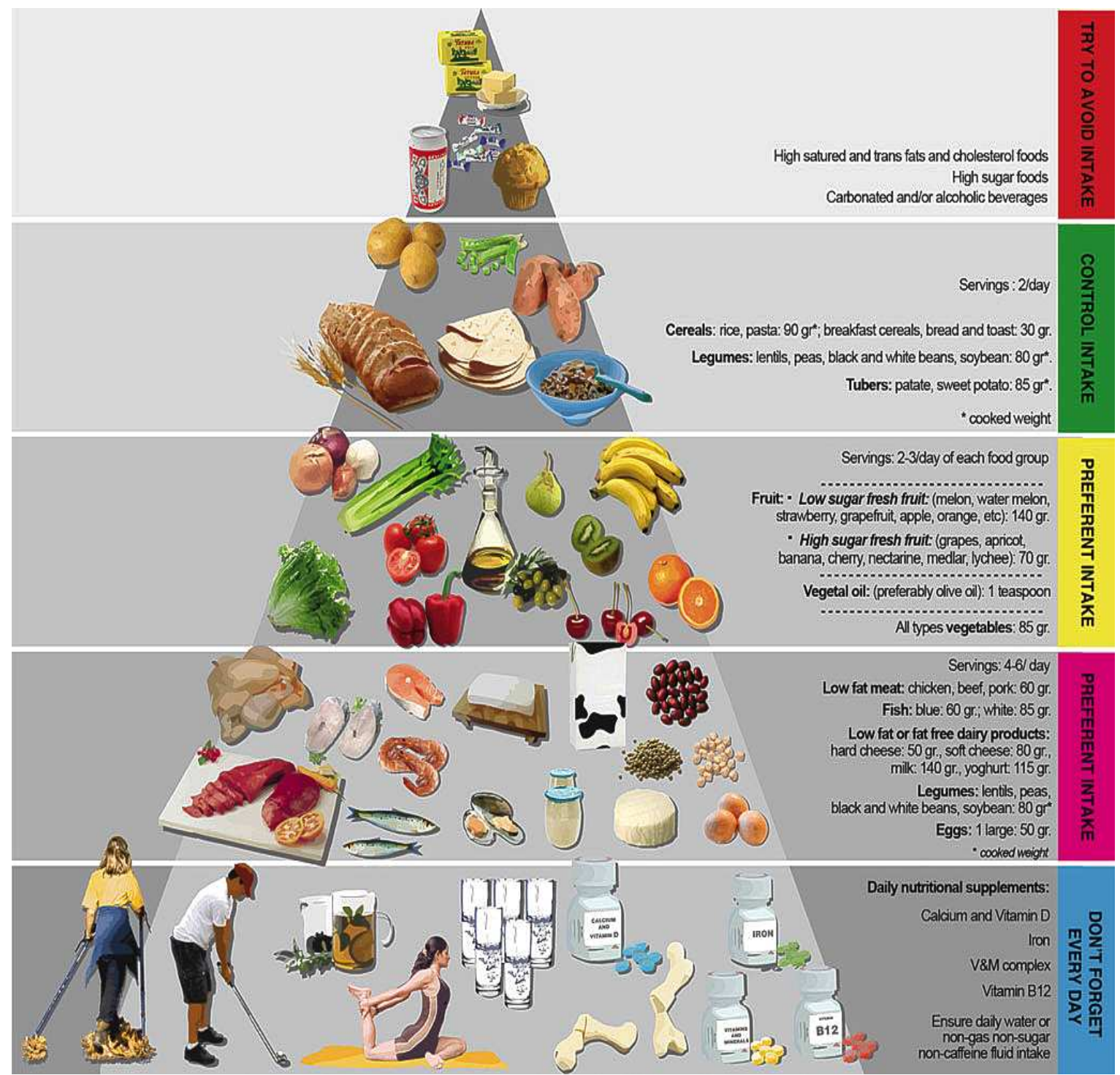

Fonte: Moizé et al. (2010).

Em relação ao consumo alimentar e práticas associadas, para cada parâmetro da PAPB foi atribuída, para este estudo, uma pontuação de 0 ou 1 , caso a paciente cumprisse ou não a recomendação, totalizando um escore máximo de 10 pontos. Os critérios compreendiam práticas diárias referentes aos últimos três meses do consumo diário de: (1) alimentos com alto teor de proteína e baixa quantidade de gordura, como carne de frango, carne de boi, carne de porco, leite e derivados, ovos e feijão, sendo recomendadas e incentivadas quatro a seis porções desses alimentos por dia (60 gramas de proteína por dia); (2) alimentos ricos em fibras e de baixo teor calórico, como frutas e hortaliças, sendo recomendadas duas a três porções de fruta (210 gramas por dia) e duas a três porções de 
hortaliças por dia (85 gramas por dia), totalizando o mínimo de 295 gramas recomendadas; (3) consumo diário de azeite de uma colher de chá (2,4 gramas por dia); (4) duas porções, no máximo, de grãos, cereais e tubérculos, como arroz, macarrão, bolos, pães, torradas e tubérculos (175 gramas por dia); (5) nenhuma quantidade de alimentos doces, como sorvetes, bombons, bebidas com alto teor de açúcar, como refrigerante e sucos artificiais; (6) nenhuma quantidade de alimentos com alto teor de gorduras, como manteiga, margarina e frituras; (7) nenhuma quantidade de bebidas alcoólicas; (8) ingestão diária de 1,8 litros de água; (9) uso contínuo, no pós-operatório, de polivitamínico e minerais, vitamina D, vitamina B12, cálcio e ferro, sem uma prescrição preestabelecida, já que essa deve ser forma individualizada. Além destes nove parâmetros, recomenda-se que o paciente seja fisicamente ativo no tempo livre. Para efeito deste trabalho, optou-se por nomear esses três últimos parâmetros, que estão localizados na base da pirâmide nutricional, de práticas associadas, pois são práticas preconizadas para os pacientes após a cirurgia bariátrica. A descrição da atividade física será apresentada no item "f", completando os 10 pontos do instrumento (Quadro 1). 
Quadro 1: Distribuição dos parâmetros avaliados

\begin{tabular}{|c|c|c|}
\hline Item da pirâmide & Recomendação & Escore \\
\hline \multicolumn{3}{|l|}{ Base da pirâmide } \\
\hline Ingestão hídrica & 1,8 litro por dia. & $\begin{array}{ll}0 & \begin{array}{l}\text { Consome diariamente menos de } 1,8 \text { litro } \\
\text { de água. }\end{array} \\
1 & \begin{array}{l}\text { Consome diariamente } 1,8 \text { litro ou mais de } \\
\text { água. }\end{array} \\
\end{array}$ \\
\hline $\begin{array}{l}\text { Prática de atividade } \\
\text { física }\end{array}$ & $\begin{array}{l}150 \text { minutos } \\
\text { semanais de } \\
\text { atividade física } \\
\text { intensidade leve ou } \\
\text { moderada. } \\
\text { ou } \\
75 \text { minutos semanais } \\
\text { de atividade física de } \\
\text { intensidade vigorosa. }\end{array}$ & $\begin{array}{l}0 \text { Não pratica ou pratica insuficientemente. } \\
1 \text { Pratica atividade recomendada. }\end{array}$ \\
\hline $\begin{array}{l}\text { Uso de suplementos } \\
\text { diariamente }\end{array}$ & $\begin{array}{l}\text { Ferro, cálcio, } \\
\text { Vitamina D, } \\
\text { Vitamina B12 e } \\
\text { complexo vitamínico } \\
\text { e minerais. }\end{array}$ & $\begin{array}{ll}0 & \begin{array}{l}\text { Uso diariamente de menos de cinco } \\
\text { suplementos. }\end{array} \\
1 & \begin{array}{l}\text { Uso diariamente de cinco ou mais } \\
\text { suplementos. }\end{array}\end{array}$ \\
\hline \multicolumn{3}{|l|}{ Primeiro nível } \\
\hline Proteína total & $\begin{array}{l}\text { 60g* ou mais por } \\
\text { dia. }\end{array}$ & $\begin{array}{ll}0 & \begin{array}{l}\text { Consome menos de } 60 \mathrm{~g} \text { de proteína por } \\
\text { dia. }\end{array} \\
1 & \text { Consome } 60 \mathrm{~g} \text { ou mais de proteína por dia. }\end{array}$ \\
\hline \multicolumn{3}{|l|}{ Segundo nível } \\
\hline Frutas e Hortaliças & $\begin{array}{l}210 \mathrm{~g} \\
85 \mathrm{~g} \\
\text { Total: 295g/dia. } \\
\text { (Valor mínimo por } \\
\text { dia) }\end{array}$ & $\begin{array}{ll}0 & \begin{array}{l}\text { Consome menos de } 295 \mathrm{~g} \text { frutas e } \\
\text { hortaliças. }\end{array} \\
1 & \begin{array}{l}\text { Consome 295g ou mais de frutas e } \\
\text { hortaliças. }\end{array} \\
\end{array}$ \\
\hline Azeite de oliva & $\begin{array}{l}1 \text { colher de chá } \\
(2,4 \mathrm{~g})\end{array}$ & $\begin{array}{ll}0 & \text { Consome menos de } 2,4 \mathrm{~g} \text { de azeite por dia. } \\
1 & \text { Consome } 2,4 \mathrm{~g} \text { ou mais de azeite por dia. }\end{array}$ \\
\hline \multicolumn{3}{|l|}{ Terceiro nível } \\
\hline $\begin{array}{l}\text { Grãos, cereais e } \\
\text { tubérculos }\end{array}$ & $\begin{array}{l}2 \text { porções por dia } \\
(175 \mathrm{~g})\end{array}$ & $\begin{array}{ll}0 & \text { Consome menos ou mais de } 175 \mathrm{~g} \text { de } \\
& \text { cereais e tubérculos. } \\
1 & \text { Consome } 175 \mathrm{~g} \text { de cereais e tubérculos. }\end{array}$ \\
\hline \multicolumn{3}{|l|}{ Quarto nível } \\
\hline Doce $^{* *}$ & Evitar o consumo. & $\begin{array}{ll}0 & \text { Consome doces. } \\
1 & \text { Não consome doces. } \\
\end{array}$ \\
\hline Gordura $* * *$ & Evitar o consumo. & $\begin{array}{ll}0 & \text { Consome gorduras. } \\
1 & \text { Não consome gorduras. }\end{array}$ \\
\hline Bebida alcoólica & Evitar o consumo. & $\begin{array}{ll}0 & \text { Consome bebida alcoólica. } \\
1 & \text { Não consome bebida alcoólica. }\end{array}$ \\
\hline
\end{tabular}


Durante a aplicação do QFAD, os participantes foram orientados a considerarem todos os dias da semana, inclusive sábados e domingos, e que o período de referência era de três meses anteriores à entrevista. Optou-se por um período de três meses para auxiliar na recordação do consumo alimentar e abranger um maior número de alimentos consumidos.

Para transformar as frequências relatadas no QFAD em frequência diária, considerou-se como referência o consumo relatado de "uma vez por dia" igual a um. Assim, foram estabelecidas as frequências diárias e as demais frequências relatadas. As frequências diárias foram descritas separadamente para cada opção de frequência do QFAD (Quadro 2). O valor da frequência diária obtido foi multiplicado pela porção do alimento consumido, resultando na porção diária consumida desse alimento. Além disso, somaram-se as demais frequências do mesmo nível da pirâmide, para assim obter a porção diária por nível.

Quadro 2: Frequência diária correspondente a cada opção do questionário de alimentar direcionado (QFAD)

\begin{tabular}{|l|c|c|}
\hline \multicolumn{1}{|c|}{ Opções do QFAD } & Cálculo & $\begin{array}{c}\text { Correspondente em frequência } \\
\text { diária }\end{array}$ \\
\hline Menos de uma vez por mês ou nunca & - & 0,00 \\
\hline $1-3$ vezes por mês & $2 \div 30$ & 0,07 \\
\hline 1 vez por semana & $1 \div 7$ & 0,14 \\
\hline 2-4 vezes por semana & $3 \div 7$ & 0,43 \\
\hline 5 ou mais vezes por semana & $5 \div 7$ & 0,71 \\
\hline 1 vez ao dia & $1 \times 1$ & 1.00 \\
\hline 2 ou mais vezes por dia & $2 \times 1$ & 2,00 \\
\hline
\end{tabular}

Para análise da composição de macronutirentes dos alimentos referidos, foi utilizado o software de Avaliação Nutricional - AvaNutri ${ }^{\circledR}$, com dados do sistema ou da Tabela Brasileira de Composição de Alimentos - TACO (TACO, 2011).

(f) Prática de atividade física: a partir do questionário de atividade física do inquérito Vigilância de Fatores e Proteção para Doenças Crônicas por Inquérito Telefônico - VIGITEL (BRASIL, 2012) (ANEXO B) foi avaliada a ocorrência de atividade física no 
tempo livre nos últimos três meses. Considerou-se fisicamente ativo no tempo livre a prática de pelo menos 150 minutos semanais de atividade física de intensidade leve ou moderada, ou pelo menos 75 minutos semanais de atividade física de intensidade vigorosa (WHO, 2011) (Quadro 3).

Quadro 3: Práticas e duração de atividade física correspondente a cada tipo de atividade física

\begin{tabular}{|c|c|c|}
\hline Práticas atividades físicas & Atividades físicas & Duração por semana \\
\hline \multirow{9}{*}{$\begin{array}{l}\text { Intensidade leve ou } \\
\text { moderada }\end{array}$} & Caminhada & \multirow{9}{*}{150 minutos } \\
\hline & Caminhada em esteira & \\
\hline & Musculação & \\
\hline & Hidroginástica & \\
\hline & Ginástica em geral & \\
\hline & Natação & \\
\hline & Artes marciais & \\
\hline & Ciclismo & \\
\hline & Voleibol & \\
\hline \multirow{6}{*}{ Intensidade vigorosa } & Corrida & \multirow{6}{*}{75 minutos } \\
\hline & Corrida em esteira & \\
\hline & Ginástica aeróbica & \\
\hline & Futebol & \\
\hline & Basquetebol & \\
\hline & Tênis & \\
\hline
\end{tabular}

(g) Dimensões do comportamento alimentar: avaliado pelo TFEQ-R21 (Tholin et al.,2005), traduzido e validado para o Brasil (NATACCI; FERREIRA JUNIOR, 2011) (ANEXO C). O TFEQ-R21 avalia por meio de 21 questões fechadas com escala tipo Likert, as três dimensões do comportamento alimentar: restrição cognitiva, alimentação emocional e descontrole alimentar. A restrição alimentar ou cognitiva é caracterizada por um conjunto de obrigações e proibições alimentares para manter ou perder peso. A alimentação emocional é referente à susceptibilidade do indivíduo em apresentar modificações na ingestão alimentar decorrente de alterações do humor ou situações desafiadoras, e o descontrole alimentar pela perda do autocontrole e consumo exagerado de alimentos, com ou sem a presença de fome (THOLIN et al., 2005). Cada dimensão recebe uma pontuação de 0 a 100, conforme proposto pelos autores, assim, quanto maior o valor, 
maior a presença do comportamento relacionado à dimensão (THOLIN et al., 2005; NATACCI; FERREIRA JÚNIOR, 2011).

\subsubsection{Análise dos dados}

Inicialmente aplicou-se o teste de normalidade de Kolmogorov-Smirnov. Para a estatística descritiva das variáveis contínuas, os dados que apresentaram distribuição normal foram expressos em média \pm desvio-padrão e os que não apresentaram distribuição normal foram expressos como medianas e suas respectivas amplitudes.

A variável dependente foi estabelecida pelo escore de qualidade da dieta e práticas associadas, de acordo com a PAPB. Consideraram-se hábitos satisfatórios ou insatisfatórios para resultados igual ou superior a 5 ou menor do que 5 , respectivamente. Foram investigados os seguintes fatores associados à qualidade da dieta e práticas associadas: idade, estado civil, renda per capita, escolaridade, tempo de cirurgia, IMC pósoperatório tardio, reganho de peso e dimensão do comportamento alimentar predominante.

Aplicou-se os testes Qui-quadrado de Pearson e o t de Student para análise de possíveis associações entre as variáveis dependentes e independentes. Para regressão logística, adotou-se o procedimento backward, para cálculo da odds ratio (OR) relativa aos fatores associados incluídos no modelo. Para a avaliação da significância estatística dos parâmetros estimados foi considerado o valor de $\mathrm{p}<0,05$ e intervalo de confiança [IC95\%]. Utilizou-se o programa Statistical Package for the Social Sciences (SPSS) versão 20 (SPSS Inc, Chicago, IL, USA).

\subsubsection{Variáveis de estudo}

(a) Variável dependente:

Qualidade da dieta e práticas associadas, de acordo com a pirâmide da cirurgia bariátrica: A variável dependente foi estabelecida pelo escore de qualidade da dieta e práticas associadas, de acordo com a PAPB. Foram considerados, respectivamente, hábitos satisfatórios ou insatisfatórios resultados iguais ou superiores a 5 , ou menores do que 5 . 
(b) Variáveis independentes:

- Dados sociodemográficos:

Idade: em anos.

Escolaridade: de acordo com a Associação Brasileira de Empresa de Pesquisa (ABEP, 2012), o grau de instrução foi categorizada em cinco grupos: "Analfabeto/fundamental 1 incompleto", "Fundamental 1 completo/Fundamental 2 incompleto", "Fundamental 2 completo/Médio incompleto", "Médio completo/Superior incompleto" e "Superior completo".

Estado civil: para melhor análise, as variáveis foram categorizadas em dois grupos: "solteiras" representando as solteiras, viúvos e separados judicialmente e divorciados, as "não solteiras", referente às casadas e união estável.

Renda per capita: categorizada de acordo com o valor do salário mínimo vigente no ano de 2013 no Brasil, que foi de R\$ 678,00 (BRASIL, 2014).

Tempo de cirurgia: em meses.

Antropometria: A partir do peso atual e da estatura aferidos foi calculado o IMC das participantes $\left(\mathrm{IMC}=\mathrm{Peso} / \mathrm{Altura}^{2}\right)$, obtendo-se a classificação do estado nutricional para adultos preconizado pela WHO (1997).

Para as pacientes que apresentaram aumento de peso no período pós-operatório, ou seja, reganho de peso, calculou-se o percentual de aumento relativo ao menor peso pósoperatório registrado no prontuário. A fórmula utilizada foi: Reganho de peso $(\%)=[$ Peso atual (kg) - Menor peso pós-operatório (kg)]/ Menor peso pós-operatório (kg) x 100.

De acordo com a evolução ponderal pós-operatória, as pacientes foram classificadas com reganho de peso (quando o reganho era superior a $10 \%$ em relação ao menor peso pós-operatório) e peso estável (quando a variação era menor do que $5 \%$ em relação ao menor peso pós-operatório). 


\title{
5 RESULTADOS: ARTIGO “QUALIDADE E COMPORTAMENTO ALIMENTAR DE MULHERES APÓS 24 MESES OU MAIS DE CIRURGIA BARIÁTRICA”
}

\author{
Artigo original \\ Comportamento Alimentar Pós-Bariátrico. \\ Apoio/financiamento: Conselho Nacional de Desenvolvimento Científico e Tecnológico \\ (CNPq) edital/chamada universal 14/2011, processo 476459/2011-7.
}

\section{Resumo}

Introdução: $O$ presente estudo teve como objetivo avaliar o consumo e o comportamento alimentar de mulheres e investigar fatores associados à qualidade da dieta, de acordo com o modelo da pirâmide nutricional adaptada ao paciente bariátrico. Métodos: Estudo transversal, realizado com mulheres submetidas há 24 meses ou mais à gastroplastia redutora em Y-de-Roux. O questionário "três fatores alimentares" e de frequência alimentar direcionado foram aplicados para avaliação do comportamento e práticas alimentares, respectivamente. Calculou-se escore de 0 a 10 para classificação da qualidade da dieta e práticas associadas, de acordo com a pirâmide nutricional adaptada ao paciente bariátrico. Valores superiores a 5 foram considerados como hábitos satisfatórios. Aplicaram-se os testes Qui-quadrado de Pearson, t de Student e regressão logística, para cálculo da odds ratio. Resultados: Participaram do estudo 95 mulheres, onde 81,1\% apresentaram hábito de vida insatisfatório. Entre as que apresentaram hábitos satisfatórios, o consumo de proteína, ingestão hídrica, uso de suplemento e prática de atividade física foram os elementos diferenciais de classificação. Pacientes com comportamento alimentar de restrição apresentaram maiores escores, enquanto o comportamento emocional foi maior no grupo de hábitos insatisfatórios. No modelo de regressão logística, a ausência de reganho de peso aumentou em $18 \%$ a chance de apresentar hábitos satisfatórios $(p=0,001)$. Conclusão: Após 24 meses de cirurgia bariátrica a maior parte das pacientes avaliadas apresentou hábitos insatisfatórios. A ausência de reganho de peso apresentou associação significativa com hábitos saudáveis. Estes resultados apontam para importância de acompanhamento nutricional a longo prazo de pacientes bariátricos, o que pode contribuir para comportamento alimentar adequado e manutenção do peso corporal saudável entre pacientes bariátricos.

Palavras chave: Obesidade. Gastroplastia. Consumo alimentar. Comportamento alimentar. 


\section{Abstract}

Background: In order to guarantee the best results after bariatric surgery in the short and long term, it was proposed an adapted nutritional pyramid model, which considers the specific nutritional needs of these patients. This study aimed to evaluate the intake and the eating behavior and investigate factors associated with quality of diet, according to the model of the nutritional pyramid adapted to the bariatric patient. Methods: Cross-sectional study with women undergoing for 24 months or more to Bypass gastroplasty in Y-of-Roux. The "three food factors" and food frequency questionnaires were applied to assess the behavior and eating habits, respectively. We calculated score 0-10 for diet quality and associated practices, according to the nutritional pyramid adapted to the bariatric patient. Values greater than 5 were considered satisfactory habits. We applied the chisquare test of Pearson, Student $t$ test and logistic regression to calculate odds ratios. We used SPSS (v.20). Results: The study evaluated 95 women, where $81.1 \%$ presented a poor quality of eating habits and associated practices, according to the parameters of the adapted pyramid. Among those who had healthy eating habits, protein intake, water intake, supplement use and physical activity were the crucial elements for this definition. Patients with restriction of feeding behavior had higher scores, while the emotional behavior was higher in the group of poor eating habits. In the logistic regression model, the absence of regained weight increased by $18 \%$ the chance to present satisfactory habits $(\mathrm{p}=$ 0.001). Conclusion: After 24 months of bariatric surgery most of the evaluated patients had unsatisfactory habits. The absence of weight regained was significantly associated with healthy habits. These results point to the importance of nutritional long-term monitoring after bariatric surgery, which may contribute to adequate eating practices and maintaining healthy body weight among these patients.

Keywords: Obesity. Gastroplasty. Food consumption. Eating behavior. 


\section{Introdução}

Considerada, atualmente, como um grave problema de saúde pública, a obesidade atinge proporções epidêmicas nos países desenvolvidos e em desenvolvimento, associada às altas taxas de morbimortalidade. Estima-se que, até 2015, aproximadamente 2,3 bilhões de adultos estarão com sobrepeso e mais de 700 milhões serão obesos ${ }^{1}$. Por sua vez, o enfrentamento, seja preventivo ou terapêutico, requer uma abordagem complexa e também multidisciplinar $^{2,3}$. Isto se faz necessário pela etiologia multifatorial da obesidade, com interações entre fatores ambientais e individuais, como aspectos genéticos, psicológicos, sociais, econômicos, comportamentais, culturais, entre outros ${ }^{4-5}$.

A opção terapêutica mais indicada para o tratamento da obesidade grave é a cirurgia bariátrica. Apesar da magnitude do emagrecimento proporcionado pela cirurgia bariátrica, algum grau de reganho de peso tem sido documentado, particularmente após os 24 meses da cirurgia ${ }^{6}$. Atribui-se o reganho de peso, em parte, às modificações decorrentes do hábito alimentar no pós-operatório tardio, com maior capacidade de consumo, associada à pior qualidade dos alimentos escolhidos, resultando em elevada ingestão energética e de baixo valor nutricional ${ }^{7}$.

Moizé et al. ${ }^{8}$ propuseram um modelo de Pirâmide Nutricional Adaptada ao Paciente Bariátrico (PAPB), como instrumento de promoção de práticas saudáveis, visando garantir melhores resultados com a cirurgia, a curto e longo prazo. Este estudo teve como objetivo avaliar o consumo e comportamento alimentar de mulheres com 24 meses ou mais de realização da cirurgia bariátrica e investigar fatores associados.

\section{Métodos}

Estudo transversal, realizado com mulheres submetidas há mais de 24 meses à gastroplastia redutora em Y-de-Roux, atendidas no ambulatório de obesidade grave do Hospital Universitário de Brasília, Distrito Federal, Brasil. Das 125 pacientes elegíveis, 95 foram localizadas e concordaram em participar da pesquisa. A coleta ocorreu entre os meses de junho a dezembro de 2013.

O presente estudo foi aprovado no Comitê de Ética e Pesquisa da Fundação de Ensino e Pesquisa em Ciências da Saúde/Secretaria de Estado de Saúde do Distrito Federal (FEPECS), projeto com protocolo 284.638. 
Foi aplicado questionário estruturado com informações sobre idade, estado civil, renda per capita, escolaridade e tempo de cirurgia. As pacientes foram pesadas em balança digital marca Welmy, com capacidade de $300 \mathrm{~kg}$ e precisão de 50 gramas (g). Foi solicitado que as pacientes ficassem descalças e com o mínimo de roupa possível. A estatura foi aferida por estadiômetro acoplado a esta mesma balança digital, com comprimento máximo de 2,0 metros e escala de $0,5 \mathrm{~cm}$, com a participante em posição ereta com os braços relaxados ao lado do corpo, pés unidos e olhar direcionado ao horizonte. Essas informações foram utilizadas para o cálculo do índice de massa corporal $\left(\mathrm{IMC} ; \mathrm{kg} / \mathrm{m}^{2}\right.$ ). Quando presente, o reganho de peso foi calculado através da fórmula: Reganho de peso $(\%)=[$ Peso atual $(\mathrm{kg})-$ Menor peso pós-operatório $(\mathrm{kg})] /$ Menor peso pós-operatório $(\mathrm{kg})$ x 100]. Considerou-se com reganho de peso as mulheres que apresentaram aumento de no mínimo $10 \%$ do menor peso saudável após a cirurgia.

O consumo alimentar foi avaliado de acordo com a $\mathrm{PAPB}^{8}$. Para cada parâmetro da PAPB foi atribuído, para este estudo, uma pontuação de 0 ou 1, caso a paciente cumprisse ou não a recomendação, totalizando escore máximo de 10 pontos. Os critérios compreendiam práticas diárias referentes aos últimos três meses do consumo diário de: (1) proteínas, mínimo 60 gramas, através da ingestão de fontes como carne de frango, carne de boi, carne de porco, peixe, leite e derivados, feijão e ovos; (2) pelo menos 295 gramas de frutas e hortaliças; (3) azeite na quantidade mínima de 2,4 gramas; (4) no máximo, 175 gramas de grãos, cereais e tubérculos, como arroz, macarrão, bolos, pães, torradas e tubérculos; (5) nenhuma quantidade de alimentos doces, como sorvetes, bombons, bebidas com alto teor de açúcar como refrigerante e sucos artificiais; (6) nenhuma quantidade de alimentos com alto teor de gorduras, como manteiga, margarina e frituras; (7) nenhuma quantidade de bebidas alcoólicas; (8) pelo menos 1,8 litros de água; e (9) polivitamínico e minerais, vitamina D, Vitamina B12, cálcio e ferro, sob a forma de suplementos. Além destes nove parâmetros, recomenda-se que o paciente seja fisicamente ativo no tempo livre, ou seja, que pratique pelo menos 150 minutos semanais de atividade de intensidade leve ou moderada, ou 75 minutos semanais de atividade de intensidade vigorosa ${ }^{9,10}$, completando os 10 pontos do instrumento. Esses três últimos parâmetros, a ingestão hídrica, o consumo de suplementos polivitaminico e minerais e a prática de atividade física, para este estudo, foram nomeados de práticas associadas, uma vez que são práticas preconizadas para essa população.

Com aplicação de questionário de frequência alimentar direcionado (QFAD) de formato vertical, com frequências categorizadas em: consumo raro ou nunca, 1 a 3 vezes 
no mês, 1 vez na semana, 2 a 4 vezes na semana, 5 a 6 vezes na semana, 1 vez ao dia, 2 ou mais vezes no dia, de acordo com o modelo de Ribeiro e colaboradores $(2006)^{11}$. Questões abertas referentes às práticas associadas também foram incluídas no questionário, para investigar a adesão às recomendações estabelecidas.

As frequências de consumo relatadas foram transformadas em frequência diária, o valor obtido multiplicado pela porção do alimento consumido, resultando na porção diária consumida desse alimento. Para análise da composição de macronutrientes e da porção consumida dos alimentos referidos, foi utilizado o software de Avaliação Nutricional AvaNutri ${ }^{\circledR}$ com dados do sistema.

O comportamento alimentar foi avaliado pela aplicação do questionário "três fatores alimentares" (TFEQ-R21) validado para população brasileira ${ }^{12}$. Este instrumento compreende 21 questões fechadas com escala tipo Likert, acerca de três dimensões do comportamento alimentar: alimentação emocional, restrição cognitiva e descontrole alimentar. A alimentação emocional representa a susceptibilidade do indivíduo para modificações na ingestão alimentar decorrente de alterações do humor ou situações desafiadoras; a restrição cognitiva é caracterizada por um conjunto de obrigações e proibições alimentares para manter ou perder peso; o descontrole alimentar, pela perda do autocontrole e consumo exagerado de alimentos, com ou sem a presença de fome ${ }^{13}$. Para cada dimensão é atribuída pontuação de 0 a 100, sendo que, quanto maior o valor, maior a presença do comportamento relacionado à dimensão ${ }^{12,13}$.

\section{Análise dos dados}

Na estatística descritiva das variáveis contínuas, aplicou-se inicialmente o teste de normalidade Kolmogorov-Smirnov. Os dados que apresentaram distribuição normal foram expressos em média \pm desvio-padrão e os que não apresentaram distribuição normal foram expressos como medianas e suas respectivas amplitudes.

A variável dependente foi estabelecida pelo escore de qualidade da dieta e práticas associadas, de acordo com a PAPB. Consideraram-se hábitos satisfatórios ou insatisfatórios para resultados igual ou superior a 5 ou menor do que 5 , respectivamente. Foram investigados os seguintes fatores associados à qualidade da dieta e práticas associadas: idade, estado civil, renda per capita, escolaridade, tempo de cirurgia, IMC pósoperatório tardio, reganho de peso e dimensão do comportamento alimentar predominante.

Aplicou-se os testes Qui-quadrado de Pearson e o t de Student para análise de possíveis associações entre as variáveis dependentes e independentes. Para regressão 
logística, adotou-se o procedimento backward, para cálculo da odds ratio (OR) relativa aos fatores associados incluídos no modelo. Para a avaliação da significância estatística dos parâmetros estimados foi considerado o valor de $\mathrm{p}<0,05$ e intervalo de confiança [IC95\%]. Utilizou-se o programa Statistical Package for the Social Sciences (SPSS) versão 20 (SPSS Inc, Chicago, IL, USA).

\section{Resultados}

Participaram do estudo 95 mulheres, sendo 64,2\% com idade até 50 anos, predominantemente não solteiras, sendo $57,9 \%$ das mulheres com renda per capita de até um salário mínimo e $60,0 \%$ com escolaridade correspondente ao ensino médio ou superior (Tabela 1).

A mediana do tempo pós-operatório foi de 60 (24-120) meses, sem diferença entre os grupos com hábitos satisfatórios e insatisfatórios, assim como o percentual da amostra com reganho de peso superior a $10 \%$. Entre as dimensões do comportamento alimentar, a restrição cognitiva apresentou maiores escores em relação às outras dimensões. Entre as pacientes com hábitos insatisfatórios, o escore do componente emocional foi significativamente superior $(\mathrm{p}=0,01)$ (Tabela 2$)$.

Na tabela 3 são apresentados os parâmetros correspondentes à qualidade da dieta e a práticas associadas. Os componentes consumo de proteína, ingestão hídrica, uso contínuo de suplemento e prática de atividade física estiveram associados nesta avaliação de hábitos satisfatórios, com diferença estatisticamente significativa entre os grupos. Apesar de pontuar de 0 a 10, o resultado máximo obtido foi um escore de 6 , com maior prevalência de indivíduos com escore menor que $5(81,1 \%, \mathrm{n}=77)$. Portanto, considerando a amostra completa, quase a totalidade dos indivíduos pesquisados encontram-se no grupo de hábitos insatisfatórios, e com diferença estatisticamente significativa entre o escore total dos grupos $(\mathrm{p}<0,001)$.

O modelo de regressão logística é apresentado na tabela 4. Após controle de todas as variáveis investigadas, observou-se que o reganho de peso apresentou associação significativa tanto com a qualidade da dieta quanto com hábitos de vida. 
Tabela 1: Características sociodemográficas de mulheres com 24 meses ou mais de gastroplastia redutora em Y-de-Roux, de acordo com hábitos de vida recomendados para pacientes bariátricos

\begin{tabular}{|c|c|c|c|c|c|c|c|}
\hline \multirow{3}{*}{ Características } & \multicolumn{4}{|c|}{ Hábitos de vida $^{1}$} & \multirow{2}{*}{\multicolumn{2}{|c|}{$\begin{array}{l}\text { Total } \\
(\mathbf{n}=95)\end{array}$}} & \multirow[t]{3}{*}{$p$} \\
\hline & \multicolumn{2}{|c|}{$\begin{array}{c}\text { Insatisfatórios } \\
(\mathrm{n}=77)\end{array}$} & \multicolumn{2}{|c|}{$\begin{array}{c}\text { Satisfatórios } \\
(n=18)\end{array}$} & & & \\
\hline & $\mathbf{n}$ & $\%$ & $\mathbf{n}$ & $\%$ & $\mathbf{n}$ & $\%$ & \\
\hline Idade (anos) & & & & & & & 0,431 \\
\hline Até 50 & 48 & 62,3 & 13 & 72,2 & 61 & 64,2 & \\
\hline Mais de 50 & 29 & 37,7 & 5 & 27,8 & 34 & 35,8 & \\
\hline Estado civil & & & & & & & 0,546 \\
\hline Solteiras & 36 & 46,8 & 7 & 38,9 & 43 & 45,3 & \\
\hline Não solteiras & 41 & 53,4 & 11 & 61,1 & 52 & 54,7 & \\
\hline Renda per capita; $\mathrm{SM}^{2}$ & & & & & & & 0,687 \\
\hline Até 1 salário mínimo & 46 & 59,7 & 9 & 50 & 55 & 57,9 & \\
\hline 1 a 2 salários mínimos & 22 & 28,6 & 7 & 38,9 & 29 & 30,5 & \\
\hline 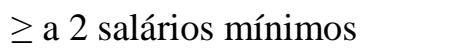 & 9 & 11,7 & 2 & 11,1 & 11 & 11,6 & \\
\hline Escolaridade & & & & & & & 0,839 \\
\hline $\begin{array}{l}\text { Analfabeto/Fundamental } \\
\text { incompleto }\end{array}$ & 17 & 22 & 2 & 11 & 19 & 20 & \\
\hline $\begin{array}{l}\text { Médio completo/Superior } \\
\text { incompleto }\end{array}$ & 35 & 45,5 & 10 & 55,6 & 45 & 47,4 & \\
\hline Superior completo & 10 & 13 & 2 & 11,1 & 12 & 12,6 & \\
\hline
\end{tabular}


Tabela 2: Tempo de cirurgia, características antropométricas e comportamento alimentar de mulheres com 24 meses ou mais de gastroplastia redutora em Y-de-Roux, de acordo com hábitos de vida recomendados para pacientes bariátricos

\begin{tabular}{|c|c|c|c|c|}
\hline \multirow[b]{2}{*}{ Variável $^{2}$} & \multicolumn{2}{|c|}{ Hábitos de vida $^{1}$} & \multirow{2}{*}{$\begin{array}{l}\text { Total } \\
(n=95)\end{array}$} & \multirow[b]{2}{*}{$p$} \\
\hline & $\begin{array}{c}\text { Insatisfatórios } \\
(\mathrm{n}=77)\end{array}$ & $\begin{array}{c}\text { Satisfatórios } \\
(n=18)\end{array}$ & & \\
\hline Tempo de cirurgia; meses ${ }^{2}$ & $60 \pm 21,5$ & $57,3 \pm 20,4$ & $59,6 \pm 21,2$ & 0,453 \\
\hline $\begin{array}{l}\text { IMC pós-operatório tardio; } \\
\mathrm{kg} / \mathrm{m}^{2}\end{array}$ & $33(19,5-53,5)$ & $34,2(22,4-37,5)$ & $33,2(19,5-53,4)$ & 0,414 \\
\hline Reganho; \% & $11(0-61,1)$ & $5,7(0-48)$ & $10,1(0-61,1)$ & 0,408 \\
\hline \multicolumn{5}{|l|}{ Comportamento alimentar ${ }^{3}$} \\
\hline Restrição & $61(11-100)$ & $67,9 \pm 22,6$ & $61 \pm 20,7$ & 0,070 \\
\hline Emocional & $45,9 \pm 31,6$ & $33,3 \pm 31,8$ & $38,8(0-100)$ & 0,010 \\
\hline Descontrole & $25,9(0-88,8)$ & $12,9(0-62,9)$ & $22,2(0-88,8)$ & 0,367 \\
\hline
\end{tabular}

1 Escore de dieta, atividade física e suplementação de micronutrientes, de acordo com PAPB (MOIZÉ et al., 2010), com valores de 0 a 10 . Foram considerados hábitos de vida satisfatórios ( $\geq 5$ pontos) e insatisfatórios (<5 pontos).

${ }^{2}$ Resultado apresentado em média \pm desvio-padrão ou mediana (máximo-mínimo), de acordo com a distribuição da variável, se normal ou não, respectivamente.

${ }^{3}$ Dimensões do comportamento alimentar de acordo como questionário "três fatores alimentares". Os escores variam de 0 a 100; quanto maior o valor, mais presente é o comportamento (NATACCI; FERREIRA JUNIOR, 2011). 
Tabela 3: Parâmetros ${ }^{1}$ associados à qualidade da dieta de mulheres com 24 meses ou mais de gastroplastia redutora em Y-de-Roux, de acordo com hábitos de vida recomendados para pacientes bariátricos

\begin{tabular}{|c|c|c|c|c|c|}
\hline \multirow[b]{2}{*}{$\begin{array}{c}\text { Parâmetros } \\
\text { PAPB }\end{array}$} & \multirow[b]{2}{*}{$\begin{array}{l}\text { Porção de } \\
\text { referência }\end{array}$} & \multicolumn{2}{|c|}{ Hábitos de vida ${ }^{2}$} & \multirow{2}{*}{$\begin{array}{l}\text { Total } \\
(\mathrm{n}=95)\end{array}$} & \multirow[b]{2}{*}{$\boldsymbol{P}^{3}$} \\
\hline & & $\begin{array}{c}\text { Insatisfatórios } \\
\quad(n=77)\end{array}$ & $\begin{array}{c}\text { Satisfatórios } \\
(n=18)\end{array}$ & & \\
\hline $\begin{array}{l}\text { Proteína; } \\
\text { g/ptn/dia }\end{array}$ & $60 \mathrm{~g} / \mathrm{ptn} / \mathrm{dia}$ & $40(14,5-129,4)$ & $61,2 \pm 29,8$ & $41(14,5-146)$ & 0,004 \\
\hline $\begin{array}{c}\text { Frutas e } \\
\text { hortaliças; g/dia }\end{array}$ & $295 \mathrm{~g} / \mathrm{dia}$ & $220,8 \pm 132,3$ & $271,2 \pm 135,1$ & $210(0-637,2)$ & 0,151 \\
\hline Azeite; g/dia & $2,4 \mathrm{~g}$ & $2,6(0-20)$ & $2,8(0-10)$ & $2,6(0-20)$ & 0,926 \\
\hline $\begin{array}{l}\text { Cereais e } \\
\text { tubérculos; } \\
\text { g/dia }\end{array}$ & $175 \mathrm{~g}$ & $172,4 \pm 93,3$ & $215,4 \pm 139,6$ & $158(2,8-561)$ & 0,115 \\
\hline Doce; $\mathrm{g} / \mathrm{dia}$ & $\begin{array}{c}\text { Não } \\
\text { recomendado }\end{array}$ & $24,2(0-400)$ & $26 \pm 27,4$ & $23,5(0-400)$ & 0,255 \\
\hline $\begin{array}{l}\text { Bebidas com } \\
\text { alto teor de } \\
\text { açúcar (ml/dia) }\end{array}$ & $\begin{array}{c}\text { Não } \\
\text { recomendado }\end{array}$ & $14(0-1200)$ & $7(0-387)$ & $14(0-1200)$ & 0,697 \\
\hline Gorduras; g/dia & $\begin{array}{c}\text { Não } \\
\text { recomendado }\end{array}$ & $10,4(0-172)$ & $10,6(0-104)$ & $10,4(0-172)$ & 0,137 \\
\hline $\begin{array}{l}\text { Bebida } \\
\text { alcoólica; } \\
\text { dose/dia }\end{array}$ & $\begin{array}{c}\text { Não } \\
\text { recomendado }\end{array}$ & $0(0-2,15)$ & $0(0-1,29)$ & $0(0-2,15)$ & 0,658 \\
\hline $\begin{array}{l}\text { Ingestão } \\
\text { hídrica; } \\
\text { litros/dia }\end{array}$ & 1,8 litros & $1(0,2-3,5)$ & $2(0,6-5)$ & $1,5(0,2-5)$ & 0,001 \\
\hline $\begin{array}{l}\text { Suplementos de } \\
\text { uso contínuo }\end{array}$ & 5 tipos $^{2}$ & $4(0-5)$ & $5(1-5)$ & $4(0-5)$ & 0,042 \\
\hline $\begin{array}{c}\text { Atividade física; } \\
\mathrm{min} / \mathrm{semana}\end{array}$ & $\begin{array}{l}150 \text { minutos } \\
\text { semanais }\end{array}$ & $106,8 \pm 157,5$ & $214,4 \pm 170,9$ & $60(0-840)$ & 0,002 \\
\hline Escore total & - & $3(0-4)$ & $5(5-6)$ & $3(0-6)$ & $<0,001$ \\
\hline $\begin{array}{l}{ }^{1} \text { Parâmetros de aco } \\
{ }^{2} \text { Escore de dieta, } \\
\text { 2010), com valores } \\
\text { (<5 pontos). } \\
{ }_{3}^{3} \text { Polivitaminico }\end{array}$ & $\begin{array}{l}\text { o com Pirâmi } \\
\text { idade física e } \\
0 \text { a } 10 \text {. Foran }\end{array}$ & $\begin{array}{l}\text { atricional Adaptada } \\
\text { mentação de micro } \\
\text { asiderados hábitos }\end{array}$ & $\begin{array}{l}\text { População Bar } \\
\text { trientes, de aco } \\
\text { vida satisfatóric }\end{array}$ & $\begin{array}{l}\text { (PAPB). } \\
\text { om PAPB (MO } \\
5 \text { pontos) e insa } \\
\end{array}$ & $\begin{array}{l}\text { é et al., } \\
\text { atórios }\end{array}$ \\
\hline
\end{tabular}


Tabela 4: Fatores associados aos hábitos de vida satisfatórios ${ }^{1}$ de mulheres com 24 meses ou mais de gastroplastia redutora em Y-de-Roux

\begin{tabular}{lcccc}
\hline & & & \multicolumn{2}{c}{ IC 95\% $^{5}$} \\
\cline { 5 - 6 } & Odds Ratio & Valor $p$ & Mínimo & Máximo \\
\hline Idade & 0,99 & 0,509 & 0,99 & 1,00 \\
Renda per capita $^{2}$ & 1,05 & 0,004 & 1,02 & 1,08 \\
Comportamento alimentar de Restrição $^{3}$ & 1,004 & $<0,001$ & 1,002 & 1,01 \\
Reganho de peso $^{4}$ & 0,82 & 0,01 & 0,71 & 0,95
\end{tabular}

${ }^{1}$ De acordo com PAPB (MOIZÉ et al., 2010) com escore de dieta, atividade física e suplementação de micronutrientes (escore de 0 a 10). Para hábitos de vida satisfatórios considerou-se valor igual ou superior a 5 pontos.

${ }^{2}$ Valor da renda per capita multiplicado por mil.

${ }^{3}$ De acordo como questionário três fatores alimentares, é caracterizada por um conjunto de obrigações e proibições alimentares para manter ou perder peso (THOLIN et al., 2005).

${ }_{5}^{4}$ Apresentar reganho de peso, considerado aumento superior a 5\% em relação ao menor peso pós-operatório.

${ }^{5}$ IC: Intervalo de confiança de $95 \%$.

\section{Discussão}

Este estudo permitiu avaliar os hábitos de vida de um grupo de mulheres com mais de 24 meses de cirurgia bariátrica, de acordo com um modelo de recomendação elaborado para pacientes bariátricos ${ }^{8}$. De maneira geral, o máximo atingido foi $60 \%$ das recomendações específicas, entretanto por um reduzido número de participantes. $\mathrm{Na}$ divisão dos grupos, quase a totalidade das mulheres encontram-se no grupo de hábitos insatisfatórios. Um indicativo de que alguma fase do tratamento não está funcionando e/ou a adesão desse paciente ao tratamento, como modificações alimentares, comportamentais e de estilos de vida, para garantir eficácia no tratamento ${ }^{14}$, não está sendo suficiente.

Sobre os dados sociodemográficos, $\operatorname{Hoffmann}^{15}$, em um estudo utilizando dados da Pesquisa de Orçamentos Familiares (POF) de 2008-2009, que analisou a probabilidade de sobrepeso e obesidade em mulheres e homens com indicadores econômicos e sociais, constatou-se que uma renda relativamente elevada e uma escolaridade acima de 10 anos contribui para reduzir a probabilidade de mulheres serem obesas. Em relação ao padrão alimentar do brasileiro, a $\mathrm{POF}^{16}$ evidenciou mudanças negativas, ao longo do tempo, tais como: teor excessivo de açúcar e gordura saturada, consumo insuficiente de frutas e hortaliças, redução no consumo de alimentos tradicionais como feijão e arroz e aumento na ingestão de alimentos industrializados. Na população bariátrica, não existem dados a respeito desta questão. 
No que se refere ao reganho de peso, ainda não está bem determinado a partir de qual percentual sua ocorrência deve ser considerada significativa. No estudo de Odom et al. ${ }^{6}$, consideraram como reganho de peso significativo valores acima de $15 \%$. Valor próximo ao encontrado por Magro et al. ${ }^{17}$, uma média de $8 \%$ de reganho após 60 meses de cirurgia sem comprometimento dos efeitos benéficos do tratamento cirúrgico. Neste estudo, observou-se resultado semelhante, com as participantes com reganho superior a 10\% do menor peso apresentado no pós-operatório. Apesar de não ter sido observada diferença da prevalência de reganho de peso na análise bi-variada, este componente apresentou associação significativa, pela regressão logística, com os hábitos de vida. Apresentar reganho de peso superior a $10 \%$ do menor peso, nesta análise, reduz em $18 \%$ a chance de ter hábitos satisfatórios. Freire et al. ${ }^{18}$ também observaram a qualidade da dieta como fator significativamente associado ao risco de reganho de peso. Estes dados sugerem a necessidade de acompanhar, de forma intensa, a qualidade da dieta e os hábitos de vida, mesmo a longo prazo do pós-operatório, visando a manutenção dos resultados alcançados com a cirurgia.

Com relação ao comportamento alimentar, sabe-se que o componente restritivo da cirurgia bariátrica pode favorecer o autocontrole e adesão de práticas saudáveis ${ }^{19}$. Estudos demostram que as cirurgias restritivas estão associadas ao aumento de comportamento de restrição cognitiva e diminuição do descontrole alimentar ${ }^{19,20}$, o que foi encontrado neste estudo. A gastroplastia redutora em Y-de-Roux é um procedimento do tipo mista, e possivelmente o componente restritivo ainda pode estar presente, apesar do período de pósoperatório. Por sua vez, o comportamento emocional refere à susceptibilidade do indivíduo em apresentar modificações no consumo alimentar decorrente a alterações do humor ou situações desafiadoras $^{12}$. No presente estudo, este componente foi significativamente mais prevalente entre as pacientes com hábitos insatisfatórios.

Acerca dos componentes de hábitos de vida, destaca-se que a ingestão de proteínas, ingestão hídrica, uso de suplementos e atividade física foram os elementos que apresentaram diferença significativa entre os grupos de hábitos de vida, satisfatórios ou não.

Sabe-se que uma dieta com aporte ideal de proteínas auxilia na melhor evolução ponderal, aumentando a saciedade, a termogênese ${ }^{21}$ e associa-se com um maior grau de preservação da massa magra ${ }^{22}$. Já uma dieta hipoproteica pode favorecer a ocorrência de hipoalbuminemia, redução da massa magra, anemia, edema, astenia e alopécia $^{23}$. A deficiência de proteína é comumente relatada na população bariátrica, e tem como causas a 
limitada capacidade individual absortiva e adaptativa, o tamanho reduzido do estômago e a baixa disponibilidade de pepsina e ácido clorídrico ${ }^{24,25}$, podendo estar relacionado também à presença de intolerância à carne ${ }^{8}$. Além disso, pode estar associada à anorexia, vômitos persistentes, diarreia, intolerância alimentar e etilismo ${ }^{26}$, sendo que tais fatores podem levar a um risco de desnutrição ${ }^{27}$. Observa-se que a suplementação proteica pode ser vista como um aspecto importante de recomendação, mesmo para pacientes com pós-operatório $\operatorname{tardio}^{28,29}$.

O consumo de frutas e hortaliças encontra-se aquém do recomendado em ambos os grupos, o qual corrobora com o estudo de Filho et al. ${ }^{30}$, que verificou um baixo consumo desses alimentos em pacientes submetidos à cirurgia bariátrica com um ano ou mais de pós-operatório. O comportamento de pacientes bariátricos parece não diferenciar da população como um todo, onde menos de $1 / 4$ da população brasileira adulta possui consumo recomendado de frutas e hortaliças, o que reflete uma baixa qualidade da dieta ${ }^{16}$. A importância de uma ingestão adequada de frutas e hortaliças se dá pela baixa densidade calórica, alto teor de fibras, minerais e vitaminas, favorecendo a plenitude e saciedade ${ }^{31}$.

Em pacientes bariátricos, estudos sobre o consumo de azeite de oliva não foram encontrados. Neste estudo, o consumo encontrou-se próximo ao recomendado por Moizé et al. ${ }^{8}$ em ambos os grupos, o que pode evidenciar a presença deste hábito.

A ingestão de cereais não foi diferente entre os grupos, sendo o consumo próximo do recomendado. Silver et al. ${ }^{32}$ observaram que pacientes com mais de dois anos de pósoperatório relatavam evitar pães e cereais em geral. Alguns estudos relataram uma intolerância mais frequente ao arroz, macarrão e pães ${ }^{30,33}$, entretanto a presença de intolerância alimentar não foi avaliada no escopo deste trabalho. Não foram encontrados mais estudos sobre consumo deste grupo de alimentos na população bariátrica de pósoperatório tardio, mas nossos resultados não sugerem que a ingestão excessiva deste grupo possa ser o componente responsável por uma dieta não saudável.

O consumo de alimentos com alto teor de açúcar e gorduras tende a ser elevado devido ao fato de estes serem palatáveis, de fácil ingestão, principalmente após longo período de pós-operatório, e exigirem menor esforço na mastigação. Observa-se uma negligência quanto ao consumo desses alimentos, uma vez que esses pacientes são desencorajados desde o pré-operatório, visto que tais alimentos não favorecem a saciedade, comprometem a perda de peso, além de desencadear efeitos indesejados, como síndrome de dumping e intolerância alimentar ${ }^{34,35}$. O consumo de alimentos doces e de refrigerantes é responsável por parte substancial do consumo de açúcar adicionado no Brasil ${ }^{35}$. Estudo 
conduzido por Freire et al. ${ }^{18}$, sobre consumo alimentar, identificou que uma pior qualidade da dieta foi caracterizada pela maior ingestão energética e maior consumo de doces, lanches, óleos e gorduras, associados ao reganho de peso. A recomendação da $\mathrm{PAPB}^{8}$ é que o consumo desses alimentos deve ser evitado, valorizando, portanto, em relação a doces e gorduras, a qualidade e não a quantidade do consumo ${ }^{8}$.

Há uma preocupação decorrente dos riscos de alcoolismo ou abuso de substâncias entre os pacientes submetidos à cirurgia bariátrica. Alguns desencadeiam uma troca de dependência ou substituição de vício, a compulsão alimentar presente no pré-operatório dá lugar a um novo vício ou outro comportamento compulsivo, como a compulsão por compras, jogos de azar ou bebida alcoólica ${ }^{36}$, que pode ser uma alternativa de enfrentamento encontrada pelo paciente ${ }^{6}$. O consumo de bebida alcoólica não é recomendado por profissionais, que recomendam a abstinência de álcool ${ }^{37}$, assim como na recomendação de Moizé et al. ${ }^{8}$, onde a bebida alcoólica encontra-se, no topo da pirâmide nutricional, dentre os alimentos que devem ser evitados. Os resultados não apontam a ingestão de álcool como determinante de hábito não saudável, talvez por se tratar de população feminina adulta ou, mesmo, de fenômeno de sub relato.

Quanto à ingestão hídrica, Valezi et al. ${ }^{38}$ e Filho et al. ${ }^{30}$ observaram, na maior parte dos pacientes pós-cirurgia bariátrica, uma ingestão hídrica menor do que o recomendado, com consumo de 500 até $1000 \mathrm{ml}$. Tal fato pode ser revertido pela introdução de líquidos em pequenas quantidades e nos intervalos entre as refeições ${ }^{30}$. Na amostra estudada, o consumo de água foi adequado apenas no grupo de hábitos satisfatórios, com diferença significativa, confirmando a literatura e sugerindo ser um componente crítico das práticas de saúde nessa população.

A GRYR pode resultar em complicações nutricionais, devido à prevalência de deficiências nutricionais no pré-operatório, redução das áreas de absorção dos nutrientes (má absorção) e baixa ingestão alimentar após a cirurgia bariátrica ${ }^{26,8}$. As deficiências mais comuns observados após GRYR são ferro, cálcio, vitamina D e vitamina B12 ${ }^{8}$. Manole ${ }^{39}$ identificou deficiências de tiamina, ácido fólico, zinco e magnésio, com complicações oculares relacionados à hipovitaminose A. Neste estudo, apesar de todas as pacientes receberem a mesma prescrição quanto ao uso de suplementação vitamínica, a adesão foi significativamente maior entre as pacientes com hábitos satisfatórios. Porém, não foi avaliada a dosagem e o tempo de uso do suplemento, o que dificulta uma análise mais criteriosa para este componente. 
A prática de atividade física, por sua contribuição no gasto energético e na manutenção de tecido muscular durante o processo de perda ponderal, é indicada no pósoperatório, sendo importante para a manutenção do peso perdido ${ }^{40}$ e efeito protetor para o reganho ${ }^{18}$. Neste estudo, foi observada diferença significante entre os grupos $(p=0,004)$. A manutenção da atividade física a longo prazo, inclusive nos tratamento clínicos tradicionais, proporciona maior perda e controle ponderal ${ }^{41}$.

Uma limitação deste estudo é o tamanho amostral, que poderia aumentar o poder estatístico das análises realizadas, mas que, dentro da realidade na qual foi executado, as possibilidades de uma amostra maior foram esgotadas. Outra limitação foi o uso de um instrumento não validado de práticas de saúde direcionadas para pacientes bariátricos.

Conclui-se que $81,1 \%$ das pacientes apresentaram um hábito de vida insatisfatório, indicando que a maioria das mulheres apresentaram uma dieta inadequada, de acordo com a recomendação proposta, o que, a longo prazo, pode contribuir para o reganho de peso. O consumo de proteínas, ingestão hídrica, o uso de suplementos e a atividade física foram elementos chaves para definição de hábitos de vida saudáveis nesta população específica. Em relação ao comportamento alimentar, observou-se que o mais presente era o relativo à restrição cognitiva e, entre os grupos, o comportamento alimentar emocional apresentou diferença estatisticamente significativa. A não presença de reganho de peso foi um fator determinante para adoção de hábitos satisfatórios, o que sugere a necessidade de uma melhoria na qualidade e na frequência do atendimento nutricional no contexto da abordagem multiprofissional de longo prazo, visto que o acompanhamento nutricional pode contribuir para favorecer melhores escolhas alimentares. Além disso, é muito importante a adesão desse paciente ao tratamento que é disponibilizado, apropriando-se de fato de sua responsabilidade mediante a complexidade deste tratamento. Neste estudo foi aplicado instrumento especifico de avaliação da dieta, com resultado significativo, o que sugere a necessidade de validação para extrapolação dos resultados.

\section{Conflito de interesses}

Nada a declarar. 


\section{Referências}

1- World Health Organization. Obesity and overweight. Geneva: 2010. Disponível em: <http://www.who.int/mediacentre/factsheets/fs311/en/index.html >. Acesso em: 13 set. 2013.

2- Gortmaker SL, Swinburn BA, Levy D, Carter R, Mabry PL, Finegood DT, Huang T, Marsh T, Moodie ML. Changing the future of obesity: science, policy, and action. Lancet, 2011; 378: 838-47.

3- Organização Pan-americana de Saúde. Estratégia e plano de ação regional para um enfoque integrado à prevenção e controle das doenças crônicas, inclusive regime alimentar, atividade física e saúde. Washington, D.C: 2007. Disponível em: 〈http://www.bvsde.paho.org/texcom/nutricion/reg-strat-cncdspt.pdf $>$. Acesso em: 7 mai 2014.

4- Swinburn BA, Sacks G, Hall KD, McPherson K, Finegood DT, Moodie ML, Gortmaker SL. The global obesity pandemic: shaped by global drivers and local environments. Lancet, 2011; 378(9793): 804-14.

5- Loss AB, Loss AB, Souza, AAP, Pitombo CA, Milent M, Madureira FAV. Avaliação da síndrome de dumping em pacientes obesos mórbidos submetidos à operação de bypass gástrico com reconstrução em Y de Roux. Rev Col Bras Cir [online], 2009; 36(5): 413-419.

6- Odom J, Zalesin KC, Washington TL, Miller WW, Hakmeh B, Zaremba DL, Altattan M, Balasubramaniam M, Gibbs DS, Krause KR, Chengelis DL, Franklin BA, McCullough PA. Behavior predictors of weight regain after bariatric surgery. Obes Surg, 2010 Mar; 20(3): 349-56.

7- American association of clinical endocrinologist, the obesity society and american society for metabolic \& bariatric surgery medical (AACE/TOS/ASMBS). Guidelines for Clinical Practice for the Perioperative Nutritional, Metabolic and nonsurgical support of the bariatric surgery patient. Surg. Obes. Relat. Dis, 2008; 4: S109-S184.

8- Moizé VL, PI-Sunyer X, Mochari H, Vidal J. Nutritional pyramid for post-gastric bypass patients. Obes Surg, 2010; 20: 1133-1141.

9- World Health Organization. Global recommendations on physical activity for health. Geneva: WHO, 2011. Disponível em: <http://whqlibdoc.who.int/publications/2010/9789241599979_eng.pdf >. Acesso em: 7 mai 2014. 
10- Haskell WL, Lee IM, Pate RR, Powell KE, Blair SN, Franklin BA, Macera CA, Heath GW, Thompson PD, Bauman A. Physical activity and public health: updated recommendation for adults from the American College of Sports Medicine and the American Heart Association. Med. Sci. Sports Exerc., 2007; 39(8): 1423-34.

11- Ribeiro AC, Sávio KEO, Rodrigues MLCF, COSTA THM, Schmitz BAS. Validação de um questionário de frequência de consumo alimentar para população adulta . Rev. Nutr. [online], 2006; 19(5): 553-562.

12- Natacci LC, Ferreira Júnior M. The three factor eating questionnaire - R21: tradução para o português e aplicação em mulheres brasileiras. Rev. Nutr. [online], 2011; 24:(3): 383-394.

13- Tholin S, Rasmussen F, Tynelius P, Karlsson J. Genetic and environmental influences on eating behavior: the Swedish Young Male Twins Study. Am J Clin Nutr. 2005, 81: 564-569.

14- Farias PM, Furtado CAS, Morales G, Santos LC, Coutinho V. Compulsão alimentar em pacientes submetidos a cirurgia bariátrica. Rev Bras Nutr Clin, 2009; 24(3): 13742.

15- Hoffmann R. Condicionantes do sobrepeso e da obesidade de adultos no Brasil, 20082009. Segurança Alimentar e Nutricional, 2012; 19(2): 1-16.

16- Instituto Brasileiro de Geografia e Estatística. Pesquisa de Orçamentos Familiares (POF) 2008/2009. Rio de Janeiro: IBGE, 2010.

17- Magro DO, Geloneze B, Delfini R, Pareja BC, Callejas F, Pareja JC. Long-term weight regain after gastric bypass: a 5-year prospective study. Obes Surg, 2008;18(6): 648-651.

18- Freire RH, Borges MC, Alvarez-Leite JI, Correia MITD. Food quality, physical activity and nutritional follow-up as determinant of weight regain after Roux-en-Y gastric Bypass. Nutrition, 2012; 28(1): 53-58.

19- Sarwer DB, Dilks RJ, West-Smith L. Dietary intake and eating behavior after bariatric surgery: threats to weight loss maintenance and strategies for success. Surg Obes Relat Dis, 2011; 7: 644-51.

20- Colles SL, Dixon JB; O'Brien PE. Grazing and loss of control related to eating: two high risk factors following bariatric surgery. Obesity, 2008; 16(3): 615-622.

21- Paddon-Jones D, Westman E, Mattes RD, Wolfe RR, Astrup A, Westerterp-Plantenga M. Protein, weight management, and satiety. Am J Clin Nutr, 2008; 87(5): 1558S$1561 S$. 
22- Westerterp-Plantenga MS, Nieuwenhuizen A, Tomé D, Soenen S, Westerterp KR. Dietary protein, weight loss, and weight maintenance. Annu Rev Nutr, 2009; 29: 2141.

23- Faintuch J, Matsuda M, Cruz MELF, Silva MM, Teivelis MP, Garrido ABJ, GamaRodrigues JJ. Severe Protein-Calorie Malnutrition after Bariatric Procedures. Obes Surg, 2004; 14(2): 175-181.

24- Bloomberg RD, Fleishman A, Nalle JE, Herron DM, Kini S. Nutritional deficiencies following bariatric surgery: what have we learned? Obes Surg, 2005; 15(2): 145-54.

25- Soares CC, Falcão MC. Abordagem nutricional nos diferentes tipos de cirurgia bariátrica. Rev Bras Nutr Clin, 2007; 22(1): 59-6.

26- Bordalo LA, Mourão DM, Bressan J. Deficiências nutricionais após cirurgia bariátrica. Acta Med Port, 2011; 24(S4): 1021-1028.

27- Moizé V, Geliebter A, Gluck ME, Yahav E, Lorence M, Colarusso T, Drake $\mathrm{V}$, Flancbaum L. Obese patients have inadequate protein intake related to protein intolerance up to 1 year following Roux-en-Y gastric bypass. Obes Surg, 2003; 13(1): 23-8.

28- Moizé V, Andreu A, Rodríguez L, Flores L, Ibarzabal A. Protein intake and lean tissue mass retention following bariatric surgery. Clinical Nutrition, 2012; 32(4): 550555.

29- Faria SL, Faria OP, Buffington C, Cardeal MA, Ito, Mk. Dietary Protein Intake and Bariatric Surgery Patients: A Review. Obes Surg. Epub, 2011 May; 18.

30- Filho AJB, Zacarias JA, Cruz MRR. Análise da evolução dietética no pós-operatório de cirurgia bariátrica. Rev Nut Pauta, 2005. Disponível em: <http://www.nutricaoempauta.com.br/layout_impressao2.php?cod=204>. Acesso em: 25 jun. 2014.

31- Sarwer DB, Wadden TA, Moore RH, Baker AW, Gibbons LM, Raper SE, Williams NN. Preoperative eating behavior, postoperative dietary adherence and weight loss following gastric bypass surgery. Surg Obes Relat Dis, 2008; 4(5): 640-6.

32- Silver HJ, Torquati A, Jensen GL, Richards WO. Weight, Dietary and Physical Activity Behaviors Two Years after Gastric Bypass. Obes Surg, 2006; 16: 859-864.

33- Quadros MRR, Savaris AL, Ferreira MV, Branco Filho AJ. Intolerância alimentar no pós-operatório de pacientes submetidos à cirurgia bariátrica. Rev Bras Nutr Clin, 2007; 22(1): 15-9. 
34- Swenson BR, Saalwachter Schulman A, Edwards MJ, Gross MP, Hedrick TL, Weltman AL, Northrup CJ, Schirmer BD, Sawyer RG.The effect of a low carbohydrate, high-protein diet on post laparoscopic gastric bypass weight loss: a prospective randomized trial. J Surg Res, 2007; 142(2): 308-13.

35- Levy RB, Claro RM, Bandoni DH, Mondini L, Monteiro CA. Disponibilidade de "açúcares de adição" no Brasil: distribuição, fontes alimentares e tendência temporal. Rev Bras Epidemiol, 2012; 15: 3-12.

36- McFadden, KM. Cross-addiction: from morbid obesity to substance abuse. Bariatric nursing and surgical patient care. 2010; 5(2): 145-178.

37- Buffington CK, Daley DL, Warthen M, Marena RT. et al. Changes in alcohol sensitivity and effects with gastric bypass. Surg Obes Relat Dis, 2006; 2(3):317-318.

38- Valezi AC, Brito SJ, Junior JM, Brito EM. Estudo do padrão alimentar tardio em obesos submetidos à derivação gástrica com bandagem em y- de- Roux: comparação entre homens e mulheres. Rev. Col. Bras. Cir., 2008; 35(6): 387-391.

39- Malone M. Recommended nutritional supplements for bariatric surgery patients. Ann Pharmacother, 2008; 42(12): 1851-8.

40- Wing RR, Hill JO. Successful weight loss maintenance. Annu Rev Nutr, 2001; 21: 323-41.

41- Andreou E, Philippou C, Papandreou D. Effects of an intervention and maintenance weight loss diet with and without exercise on anthropometric indices in overweight and obese healthy women. Ann Nutr Metab, 2011; 59(2-4): 187-92. 


\section{CONCLUSÕES}

Conclui-se que o consumo de proteínas, ingestão hídrica, o uso de suplementos e prática de atividade física foram elementos chaves para definição de hábitos de vida satisfatórios nesta população específica. Contudo, 81,1\% das pacientes apresentaram hábitos de vida insatisfatórios.

Em relação ao comportamento alimentar, observou-se que o mais presente era o relativo à restrição cognitiva, caracterizada por um conjunto de obrigações e proibições alimentares para manter ou perder peso. Este fato era esperado, visto que pacientes submetidos a GRYR são obesos ou ex-obesos e muitos temem a recuperação do peso perdido. Além disso, a própria cirurgia favorece um comportamento restritivo. Isoladamente, este comportamento não parece ser efetivo para garantir a manutenção de peso. E, entre os grupos, o comportamento alimentar emocional apresentou diferença estatisticamente significativa.

Dentre os fatores associados à adesão de hábitos de vida recomendados para pacientes bariátricos, a não presença de reganho de peso foi o fator associado à adoção de hábitos satisfatórios. Isto sugere a necessidade de uma melhoria na qualidade e na frequência do atendimento nutricional no contexto da abordagem multiprofissional e interdisciplinar de curto e longo prazo, visto que o acompanhamento nutricional pode contribuir para favorecer melhores escolhas alimentares. Além disso, é muito importante a adesão desse paciente ao tratamento que é disponibilizado, apropriando-se de fato de sua responsabilidade mediante a complexidade deste tratamento. 


\section{CONSIDERACÕES FINAIS}

O presente estudo inovou ao avaliar o consumo e o comportamento alimentar e as práticas associadas, como a ingestão hídrica, uso de suplementos e a prática de atividade física, que são fundamentais para o tratamento a longo prazo dessa população e que têm sido pouco explorados em outros estudos. È recomendável que outros estudos desta natureza sejam realizados com a elaboração de um instrumento de avaliação do consumo validado para essa população, com a análise do consumo de macro e micronutrientes, inclusive com a utilização de mais de um tipo de instrumento de avaliação do consumo alimentar.

É importante que os pacientes sejam conscientizados pelos profissionais da equipe multidisciplinar sobre a necessidade da efetiva mudança de comportamento e incentivados a responderem de forma mais saudável às situações que são impostas no seu cotidiano. Com alterações no ambiente obesogênico, as escolhas por hábitos de vida mais saudáveis são facilitadas. Como podemos perceber neste estudo, a maioria das práticas são modificáveis e dependem de orientação e também do interesse e adesão do paciente pelo tratamento, como o consumo de proteína, ingestão hídrica, prática de atividade física e uso contínuo dos suplementos. 


\section{REFERÊNCIAS}

AMERICAN ASSOCIATION OF CLINICAL ENDOCRINOLOGIST, THE OBESITY SOCIETY AND AMERICAN SOCIETY FOR METABOLIC \& BARIATRIC SURGERY MEDICAL (AACE/TOS/ASMBS). Guidelines for Clinical Practice for the Perioperative Nutritional, Metabolic and nonsurgical support of the bariatric surgery patient. Surg Obes Relat Dis, v. 4, p. 109-184, 2008.

ASSOCIAÇÃO BRASILEIRA DE EMPRESA DE PESQUISA (ABEP). Critério de Classificação Econômica Brasil. Disponível em:

<http://www.abep.org/new/Servicos/Download.aspx?id=07>. Acesso em: 07 maio 2014.

AVELINO, G. F.; PREVIDELli, A. N.; CASTRO, M. A.; MARCHIONI, D. M. L.; FISBERG, R. M. Sub-relato da ingestão energética e fatores associados em estudo de base populacional. Cad. Saúde Pública, v. 30, n. 3, p. 663-668, 2014.

BARHAM, K.; DAYYEH, A.; LAUTZ, D. B.; THOMPSON, C. C. Gastrojejunal stoma diameter predicts weight regain after roux-en-y gastric bypass. Clin Gastroenterol and Hepatol, v. 9, p. 228-233, 2011.

BIRÓ, G.; HULSHOF, K. F. A. M.; OVESEN, L.; AMORIM CRUZ, J. A. Selection of methodology to assess food intake. Eur J Clin Nutr, v. 56, n. 2, p. 25-32, 2002.

BOHM, C. H.; GIMENES, L. S. Automonitoramento como técnica terapêutica e de avaliação comportamental. Revista Psicolo, v. 1, n. 1, p. 88-100, 2008.

BORDALO, L. A.; TEIXEIRA, T. F. S.; BRESSAN, J.; MOURÃO, D. M. Cirurgia bariátrica: como e porque suplementar. Rev Assoc Med Bras, v. 57, n. 1, p. 113-120, 2011.

BRASIL. Ministério da Saúde. Portaria GM/MS nº 628, de 26 de abril de 2001. Brasília. Disponível em: <http://www.saude.mg.gov.br/atos_normativos/legislacaosanitaria/estabelecimentos-de-saude/cirurgia-bariatrica/portaria_0628.pdf $>$. Acesso em: 25 mar. 2013.

. Ministério da Saúde. Portaria MS/GM n 425, de 19 de março de 2013. Brasília. Disponível em: $<$ http://bvsms.saude.gov.br/bvs/saudelegis/gm/2013/prt0425_19_03_2013.html $>$. Acesso em: 25 mar. 2013.

. Ministério da Saúde. Portaria MS/GM no 493, de 31 de agosto de 2007. Brasília. Disponível em: 〈http://w3.datasus.gov.br/sihd/Portarias/portaria2007〉. Acesso em: $21 \mathrm{fev}$. 2013.

. Ministério da Saúde. Secretaria de Atenção à Saúde. Relatório de Gestão 2011. Brasília: Ministério da Saúde, 2012. 
Ministério da Saúde. Secretaria de Vigilância em Saúde. Secretaria de Gestão Estratégica e Participativa. Vigitel Brasil 2011: vigilância de fatores de risco e proteção para doenças crônicas por inquérito telefônico. Brasília: Ministério da Saúde, 2012.

Portal do trabalho e emprego. Salário mínimo. 2014. Disponível em: <http://portal.met.gov.br/sal_min/>. Acesso em: 15 abr. 2014.

BROWNELL, K. D.; HECKERMAN, C. L.; WESTLAKE, R. J. The behavioral control of obesity: A descriptive analysis of a large-scale program. J Clin Psychol, v. 35, n. 4, p. 864-869, 2006.

BUCHWALD, H.; AVIDOR, Y.; BRAUNWALD, E. et al. Bariatric surgery: a systematic review and meta-analysis. Jama, v. 292, n. 14, p. 1724-1728, 2004.

BUZZARD, M. 24 hour dietary recall and food record methods. In: WILLETT, W. C. Nutritional Epidemiology. 2. ed. Oxford: Oxford University Press, 1998. p. 50-73.

CADE, J.; THOMPSON, R.; BURLEY, V.; WARM, D. Development, validation and utilization of food-frequency questionnaires - a review. Public Health Nutrition, v. 5, n. 4, p. 567-587, 2002.

CAMPOS, J. M.; LINS, D. C.; SILVA, L. B.; ARAUJO-JUNIOR, J. G. C.; ZEVE, J. L. M.; FERRAZ, A. A. B. Cirurgia metabólica, reganho de peso e recidiva do diabete. Arq Bras Cir DIG, v. 26, n. 1, 2013.

CARDOSO, M. A. Desenvolvimento, validação e aplicação de questionário de frequência alimentar em estudos epidemiológicos. In: KAC, G.; SICHIERI, R.; GIGANTE, D. P. Epidemiologia Nutricional. Rio de Janeiro: Fiocruz/Atheneu, 2007. cap. 11, p. 201-212.

CHRISTOU, N.; EFTHIMIOU, E. Five-year outcomes of laparoscopic adjustable gastric banding end laparoscopic Roux-en-Y gastric bypass in a comprehensive bariatric surgery program in Canada. Can J Surg, v. 52, n. 6, 2009.

COLLES, S. L.; DIXON, J. B.; O'BRIEN, P. E. Grazing and loss of control related to eating: two high risk factors following bariatric surgery. Obesity, v. 16, n. 3, p. 615-622, 2008.

COSTA, L. D.; VALEZI, A. C.; MATSUO T.; DICHI, I.; DICHI, J. B. Repercussão da perda de peso sobre parâmetros nutricionais e metabólicos de pacientes obesos graves após um ano de gastroplastia em Y-de-Roux. Rev Col Bras Cir, v. 37, n. 2, 2010.

CROOKES, P. F. Surgical Treatment of Morbid Obesity. Ann Rev Med, v. 57, p. 243264, 2006.

CRUZ, M. R. R.; MORIMOTO, I. M. I. Intervenção nutricional no tratamento cirúrgico da obesidade mórbida: resultados de um protocolo diferenciado. Rev Nut, v. 17, n. 2, p. 263-272, 2004. 
CUMMINGS, D. E. Metabolic surgery for type 2 diabetes. Nature Medicine, v. 18, n. 5, p. 656-658, 2012.

DALCANALE, L.; OLIVEIRA, C. P. M. S.; FAINTUCH, J.; NOGUEIRA, M. A.; RONDÓ, P.; LIMA, V. M. R. L.; MENDONÇA, S.; PAJECKI, D.; MANCINI, M.; CARRILHO, F. J. Long-Term Nutritional Outcome After Gastric Bypass. Obes Surg, v. 20, p. 181-187, 2010.

DI GIORGI, M.; ROSEN, D. J.; CHOI, J. J. et al. Re-emergence of diabetes after gastric bypass in patients with mid- to long-term follow-up. Surg Obes Relat Dis, v. 6, n. 3, p. 249-53, 2010.

EVANGELISTA, L. F; CAMPOS, J. M. Evolução histórica e avaliação da eficácia da cirurgia bariátrica. In: BURGOS, G. P. A; LIMA, D. S. C; COELHO, P. B. P. Nutrição em cirurgia bariátrica. Rio de Janeiro: Rubio, 2011.

FARIA, S. L.; KELLY, E.; FARIA, O. P. Energy expenditure and weight regain in patients submitted to roux-en-y gastric bypass. Obes Surg, v. 19, p. 856- 859, 2009.

FISBERG, R. M.; SLATER, E.; MARCHIONI, D. M. L.; MARTINI, L. A. Inquéritos alimentares: métodos e bases cientificas. Barueri: Manole, 2005.

FREIRE, R.H.; BORGES, M. C.; ALVAREZ-LEITE, J. I.; CORREIA, M. I. T. D. Food quality, physical activity and nutritional follow-up as determinant of weight regain after Roux-en-Y gastric Bypass. Nutrition, v. 28, p. 53-58, 2012.

GARRIDO JR, A. B. Cirurgia da obesidade. Sociedade Brasileira de Cirurgia Bariátrica. São Paulo: Atheneu, 2006.

GOMES, A. A.; LEÃO, L. S. C. S. Prevalência de sub-relato e super-relato de ingestão energética em população ambulatorial do Rio de Janeiro, Brasil. Cad Saúde Colet, v. 2, n. 19, p. 197-202, 2011.

GUEDES A. C.; VIRGENS A. A.; NASCIMENTO, C. E.; VIEIRA, M. P. B. Qualidade de vida em pacientes submetidos à cirurgia bariátrica do tipo Derivação Biliopancreática com Preservação Gástrica (DBPPG). Rev Inst Ciência Saúde, v. 27, n. 3, p. 209-213, 2009.

GUERRA, C. S. C. D.; JIMÉNEZ, A. L. Analysys of Weight Loss with the Biliopancreatic Diversion of Larrad: Absolut Failures or Relative Successes? Obes Surg, v. 12, p. 249$252,2002$.

HEBER, D.; GREENWAY, F. L.; KAPLAN, L. M.; LIVINGSTON, E.; SALVADOR, J.; STILL, C. Endocrine and Nutritional Management of the Post-Bariatric Surgery Patient: An Endocrine Society Clinical Practice Guideline. J Clin Endocrinol Metab, v. 95, p. 4823-4843, 2010.

HOJO, V. E. S.; MELO, J. M.; NOBRE, L. N. Alterações hormonais após cirurgia bariátrica. Rev Bras de Nutr Clin, v. 22, n. 1, p. 77-82, 2007. 
INSTITUTO BRASILEIRO DE GEOGRAFIA E ESTATÍSTICA (IBGE). Pesquisa de Orçamentos Familiares (POF) - 2008/2009. Rio de Janeiro: IBGE, 2010.

KAC, G.; SICHIERI, R.; GIGANTE, D. P. Epidemiologia nutricional. Rio de Janeiro: Fiocruz/Atheneu, 2007.

KOFMAN, M. D.; LENT, M. R.; SWENCIONIS, C. Maladaptive eating patterns, quality of life, and weight outcomes following gastric bypass: results of an internet survey.

Obesity, v. 18, p. 1938-1943, 2010.

LOSS, A. B.; SOUZA, A. A. P.; PITOMBO, C. A.; MILENT, M.; MADUREIRA, F. A. $\mathrm{V}$. Avaliação da síndrome de dumping em pacientes obesos mórbidos submetidos à operação de bypass gástrico com reconstrução em Y-de-Roux. Rev Col Bras Cir [online], v. 36, n. 5, p. 413-419, 2009.

MAGRO, D. O.; DELFINI, R.; PAREJA, B. C.; CALLEJAS, F.; PAREJA, J. C. Longterm weight regain after gastric bypass: a 5-year prospective study. Obes Surg, v. 18, p. 648-651, 2008.

MARCASON, W. What are the dietary guidelines following bariatric surgery? J Am Diet Assoc, v. 104, p. 487-488, 2004.

MCFADDEN, K. M. Cross-addiction: from morbid obesity to substance abuse. Bariatric Nursing and Surgical Patient Care, v. 5, n. 2, p. 145-178, 2010.

MOIZÉ V. L.; PI-SUNYER, X.; MOCHARI, H.; VIDAL, J. Nutritional pyramid for postgastric by-pass patients. Obes Surg, v. 20, p. 1133-1141, 2010.

MOIZÉ, V. L.; GELIEBTER, A.; GLUCK, M. E.; YAHAV, E.; LORENCE, M.; COLARUSSO, T.; DRAKE, V.; FLANCBAUM, L. Obese patients have inadequate protein intake related to protein intolerance up to 1 year following Roux-en-Y gastric bypass. Obes Surg, v. 13, n. 1, p. 23-28, 2003.

MONGOL, P.; CHOSIDOW, D.; MARMUSE, J. P. Laparoscopic Gastric Bypass versus Laparoscopic Adjustable Gastric Banding in the Super-obese: A Comparative Study of 290 Patients. Obes Surg, v. 15, n. 1, p. 76-81, 2005.

MONTEIRO JÚNIOR, F. C.; SILVA JÚNIOR, W. S.; SALGADO FILHO, N.; FERREIRA, P. A. M; ARAÚJO, G. F.; MANDARINO, N. R. et al. Efeito da perda ponderal induzida pela cirurgia bariátrica sobre a prevalência de síndrome metabólica. Arq Bras Cardiol, v. 92, n. 6, p. 452-56, 2009.

NATACCI, L. C.; FERREIRA JUNIOR, M. The three factor eating questionnaire R21: tradução para o português e aplicação em mulheres brasileiras. Rev Nutr, v. 24, n. 3, p. 383-394, 2011.

NIEGO, S. H.; KOFMAN, M. D.; WEISS, J. J. et al. Binge eating in the bariatric surgery population: A review of the literature. Int J Eat Disord, v. 40, n. 4, p. 149-359, 2007. 
O'DONNELL, K. Bariatric Surgery: Nutritional Concerns on the Weigh Down. Practical gastroenterology, 2004. Disponível em:

<http://www.paxysarkia.net/Download/Article_Nutritional\%20consequences\%20of\%20Ba riatric\%20surgery.pdf>. Acesso em: 09 nov. 2014.

ODOM, J.; ZALESIN, K. C.; WASHINGTON, T. L. et al. Behavior predictors of weight regain after bariatric surgery. Obes Surg, v. 20, p. 349-356, 2010.

OLIVEIRA, M. L. Estimativas dos custos da obesidade para o Sistema Único de Saúde no Brasil. Brasília: UNB, 2013. Tese [Doutorado], Brasília: Universidade de Brasília, 2013.

ORGANIZAÇÃO PAN-AMERICANA DE SAÚDE (OPAS). Estratégia e plano de ação regional para um enfoque integrado à prevenção e controle das doenças crônicas, inclusive regime alimentar, atividade física e saúde. Washington, D.C: 2007. Disponível em:

$<$ http://new.paho.org/bra/index.php?option=com_docman\&task=cat_view\&gid=1116\&Ite

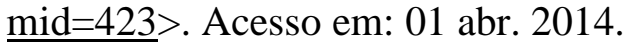

PADDON-JONES, D.; WESTMAN, E.; MATTES, R. D.; WOLFE, R. R.; ASTRUP, A.; WESTERTERP-PLANTENGA, M. Protein, weight management, and satiety. Am J Clin Nutr, v. 87, n. 5, p. 1558S-1561S, 2008.

PEDROSA, I. V.; BURGOS, M. G. P. A.; SOUZA, N. C.; MORAIS, C. N. Aspectos nutricionais em obesos antes e após a cirurgia bariátrica. Rev Col Bras Cir, v. 36, n. 4, p. 316-322, 2009.

PEREIRA, R. A.; SICHIERI, R. Métodos de avaliação do consumo de alimentos. In: KAC, G.; SICHIERI, R.; GIGANTE, D. P. Epidemiologia Nutricional. Rio de Janeiro: Fiocruz/Atheneu, 2007. p. 181-200.

POPKIN, B. M.; GORDON-LARSEN, P. The nutrition transition: worldwide obesity dynamics and their determinants. Int J Obes Relat Metab Disord, v. 28, n. 3, p. 2-9, 2004.

PREVEDELLO, C. F.; COLPO, E; MAYER, E. T.; COPETTI, H. Análise do impacto da cirurgia bariátrica em uma população do centro do Estado do Rio Grande do Sul utilizando o método BAROS. Arq Gastroenterol, v. 46, n. 3, p. 199-203, 2009.

RAFTOPOULOS, I.; BERNSTEIN, B.; O'HARA, C.; RUBY, J. A.; CHHATRALA, R.; CARTY, J. Protein intake compliance of morbidly obese patients undergoing bariatric surgery and its effect on weight loss and biochemical parameters. Surg Obes Relat Dis, jul. 2011.

REBOLLEDO, A.; BASFI-FER, K.; ROJAS, P.; CODOCEO, J.; INOSTROZA, J.; CARRASCO, F.; RUZ, M. Evolución y calidad de la alimentación de mujeres con obesidad severa y mórbida sometidas a bypass gástrico. Archivos Latinoamericanos de Nutrición, v. 50, n. 1, p. 7-13. 2009. 
RIBEIRO, A. C.; SÁVIO, K. E. O.; RODRIGUES, M. L. C. F.; COSTA, T. H. M.;

SCHMITZ, B. A. S. Validação de um questionário de frequência de consumo alimentar para população adulta. Rev Nutr, v. 19, n. 5, p. 553-562, 2006.

SÁ, V. C.; FERRAZ, A. A.; CAMPOS, J. M. et al. Gastric bypass in the treatment of type 2 diabetes in patients with a BMI of 30 to $35 \mathrm{~kg} / \mathrm{m} 2$. Obes Surg, v. 21, n. 3, p. 283-287, 2011.

SANTOS, L. M. P.; OLIVEIRA, I. V.; PETERS, L. R. et al. Trends in Morbid Obesity and in Bariatric Surgeries Covered by the Brazilian Public Health System. Obes Surg, v. 20, p. 943-948, 2010.

SARWER, D. B.; WADDEN, T. A.; MOORE, R. H.; BAKER, A.W.; GIBBONS, L. M.; RAPER, S. E.; WILLIAMS, N. N. Preoperative eating behavior, postoperative dietary adherence and weight loss following gastric bypass surgery. Surg Obes Relat Dis, v. 4 , n. 5, p. 640-646, 2008.

SCAGLIUSI, F. B.; LANCHA JUNIOR, A. H. Subnotificação da ingestão energética na avaliação do consumo alimentar. Rev Nutr, v. 16, n. 4, p. 471-481, 2003.

SCHERNTHANER, G.; BRIX, J.; KOPP, H. P.; SCHERNTHANER, G. S. Cure of type 2 diabetes by metabolic surgery? a critical analysis of the evidence in 2010. Diabetes Care, v. 34, n. 2, p. 355-360, 2011.

SHAH, M.; SIMHA, V.; GARG, A. Long-term impact of bariatric surgery on body weight, comorbidities, and nutritional status. The Journal of Clinical Endocrinology \& Metabolism, v. 91, n. 11, p. 4223-4231, 2006.

SILVA, S. A.; BURGOS, M. G. P. A.; SANTOS, E. M. C.; BATISTA, J. E. M.; BION, F. M. Consumo alimentar de obesos em períodos pré e pós-operatórios de cirurgia bariátrica. An Fac Med Univ Fed Pernamb, v. 50, n. 1, p. 15-18, 2005.

SILVA-NETO, E. F.; VÁZQUEZ, C. M. P.; SOARES, F. M.; SILVA, D. G.; SOUZA, M. F. C.; BARBOSA, K. B. F. Cirurgia bariátrica reverte risco metabólico em pacientes assistidos em nível ambulatorial. Arq Bras Cir Dig, v. 27, n. 1, p. 38-42, 2014.

SILVER, H. J.; TORQUATI, A.; JENSEN, G. L.; RICHARDS, W. O. Weight, dietary and physical activity behaviors two years after gastric bypass. Obes Surg, v. 16, p. 859-864, 2006.

SJÖSTRÖM, L.; LINDROOS, A.; PELTONEN, A. Lifestyle, diabetes, and cardiovascular risk factors 10 years after bariatric surgery. N Engl J Med, v. 351, n. 6, p. 2683-2693, 2004.

SLATER, B.; LIMA, F. E. L. Validade e reprodutibilidade dos métodos de inquérito alimentar. In: FISBERG, R. M. et al. Inquéritos alimentares: métodos e bases científicos. São Paulo: Manole, 2005. p. 108-128. 
SLATER, B.; PHILIPPI, S. T.; FISBERG, R. M.; LATORRE, M. R. D. O. Validation of a semiquantitative adolescent food frequency questionnaire applied at a public school in São Paulo, Brazil. Eur J Clin Nutr, v. 57, n. 5, p. 629-635, 2003.

\section{SOCIEDADE BRASILEIRA DE CIRURGIA BARIÁTRICA E METABÓLICA} (SBCBM). Técnicas Cirúrgicas. Disponível em:

$\langle$ http://www.sbcbm.org.br/wordpress/tratamento-cirurgico/cirurgia-laparoscopica/> . Acesso em: 25 mar. 2014.

STRUNKARD, A. J.; MESSICK, S. The three-factor eating questionnaire to measure dietary restraint, disinhibition and hunger. J Psychosom Res, v. 29, p. 71-83, 1985.

SWINBURN, B. A.; SACKS, G.; HALL, K. D.; MCPHERSON, K.; FINEGOOD, D. T.; MOODIE, M. L.; GORTMAKER, S. L. The global obesity pandemic: shaped by global drivers and local environments. Lancet, v. 378, n. 9793, p. 804-814, 2011.

TABELA BRASILEIRA DE COMPOSIÇÃO DE ALIMENTOS (TACO). Núcleo de Estudos e Pesquisas em Alimentação. 4. ed. rev. e ampl. Campinas: NEPA- UNICAMP, 2011.

THEREAUX, J.; CZERNICHOW, S.; CORIGLIANO, N.; POITOU, C.; OPPERT, J-M.; BOUILLOT, J. L. Five-Year Outcomes of Gastric Bypass for Super-Super-Obesity (BMI $\geq 60 \mathrm{~kg} / \mathrm{m}^{2}$ ): A Case Matched Study. Surg Obes Relat Dis, 2014.

THOLIN, S.; RASMUSSEN, F.; TYNELIUS, P.; KARLSSON, J. Genetic and environmental influences on eating behavior: the Swedish Young Male Twins Study. Am J Clin Nutr, v. 81, p. 564-569, 2005.

THOMPSON, F. E.; BYERS, T. Dietary Assessment Resource Manual. American Institute of Nutrition. Journal Nutrition, v. 124, p. 2245-2317, 1994.

TORAL, N.; SLATER, B. Abordagem do modelo transteórico no comportamento alimentar. Ciência Saúde coletiva, v. 12, n. 6, 2007. Disponível em: <http://www.scielo.br/scielo.php?script=sci_arttext\&pid=S1413-81232007000600025 >. Acesso em: 13 ago. 2014.

TUCKER, O. N.; SZOMSTEIN, S.; ROSENTHAL, R. J. Nutritional consequences of weight-loss surgery. Med Clin North Am, v. 91, n. 3, p. 499-514, 2007.

WESTERTERP-PLANTENGA, M. Protein, weight management, and satiety. Am J Clin Nutr, v. 87, p. 1558-1561, 2008.

WORLD HEALTH ORGANIZATION (WHO). Global recommendations on physical activity for health. Geneva: World Health Organization, 2011. Disponível em: <http://whqlibdoc.who.int/publications/2010/9789241599979_eng.pdf>. Acesso em: 7 maio 2014.

Global strategy on diet, physical activity and health. Fifty seventh world assembly. Geneva: World Health Organization, 2004. 
Obesity and overweight. Geneva, 2010. Disponível em:

$\langle$ http://www.who.int/mediacentre/factsheets/fs311/en/index.html $>$. Acesso em: 22 abr. 2014.

Obesity: preventing and managing the global epidemic. Technical Report Series. $\mathrm{n}$. 894. Geneva: World Health Organization, 2000.

Obesity. Preventing and managing the global epidemic. Report of a WHO

Consultation on Obesity. Geneva: World Health Organization, 1997. p. 107-158.

WORLD HEALTH ORGANIZATION (WHO). Preventing noncommunicable dieases in the workplace through diet and physical activity. WHO/ World Economic Forum report of a joint event. Geneva: World Health Organization, 2008.

WULFERT, E.; GREENWAY, D. E.; FARKAS, P.; HAYES, E. C.; DOUGUER, M. J. Correlation between self-reported rigidity and rule-governed insensitivity to operant contingencies. Journal of the Experimental Analysis os Behavior, v. 27, p. 659-671, 1994. 


\title{
APÊNDICE A
}

\section{Termo de Consentimento Livre e Esclarecido}

\author{
$\Psi$ \\ Universidade de Brasília / Faculdade de Ciências da Saúde / Departamento de Nutrição \\ Programa de Pós-graduação em Nutrição Humana
}

Projeto: Efeitos Metabólicos e Nutricionais da Suplementação Proteica para Tratamento de Reganho de Peso no Pós-Operatório Tardio de Cirurgia Bariátrica

A senhora está sendo convidada a participar de uma pesquisa sobre o uso de uma dieta pobre em calorias no tratamento de pacientes que realizaram a cirurgia bariátrica, mas que voltaram a aumentar de peso. Esta pesquisa tem o objetivo de auxiliar a senhora a reduzir seu peso corporal e evitar a continuação do reganho de peso e a piora no quadro de doenças e complicações associadas a este reganho. Metade dos pacientes do estudo, escolhidos por sorteio, além de seguir a dieta pobre em caloria, receberá suplemento de proteína (proteína do soro do leite) que deverá ser consumido diariamente; o outro grupo seguirá a dieta pobre em calorias, mas sem o suplemento de proteína. Sendo de um grupo ou de outro, o acompanhamento clínico e nutricional irá ajudar a controlar o seu peso, doenças associadas e melhorar sua qualidade de vida; portanto, independente do grupo que a senhora for inserida, terá benefícios para sua saúde durante a participação nesta pesquisa.

A pesquisa será desenvolvida por meio de consultas quinzenais, no Hospital Universitário de Brasília (HUB); as datas e horários das consultas serão definidos com antecedência em comum acordo com a senhora durante 4 meses, nos quais serão medidos seu peso, quantidade de gordura do corpo e gasto de energia em momentos combinados anteriormente ao encontro. Serão coletados no seu prontuário dados sobre a evolução de seu peso durante o período de tratamento nesta Instituição. Os exames necessários serão realizados por meio de bioimpedância e calorimetria indireta; ambos são exames que não causam dor e não são invasivos, com duração de 45 minutos. A senhora deverá permanecer em repouso durante cerca de 30 minutos, deitada em uma maca, sem se movimentar e acordada, para medir seu gasto de energia e a quantidade de gordura e massa muscular de seu corpo. Além disso, serão feitas perguntas sobre a qualidade e quantidade das refeições que a senhora realiza e será necessário coletar sangue em jejum de 12 horas, ao início, no meio e ao final da pesquisa, para exames bioquímicos e dosagens das concentrações de 
hormônios no sangue que interferem em seu apetite. A senhora receberá uma dieta elaborada de forma individual a ser seguida durante a pesquisa. Estes procedimentos não trarão custos financeiros, não haverá riscos para sua saúde e não comprometerão de qualquer forma o seu horário de atendimento nesta instituição. A senhora poderá tirar suas dúvidas a qualquer momento no decorrer de sua participação na pesquisa. Quaisquer alterações encontradas nos resultados dos seus exames serão imediatamente comunicadas à senhora e ao seu médico e o tratamento será garantido no próprio serviço.

Espera-se que esta pesquisa venha favorecer a melhora da sua qualidade de vida a partir da adoção desta dieta, evitando complicações da obesidade e auxiliando na sua perda de peso.

As informações e resultados encontrados no final da pesquisa poderão ser publicados em revistas e eventos científicos, mantendo o compromisso de total sigilo da sua identidade. Os resultados deste estudo serão apresentados ao Programa de PósGraduação em Nutrição Humana, ficando também à sua disposição. Ao final da pesquisa, a senhora receberá um documento com os resultados da pesquisa. Os resultados dos exames e da avaliação de prontuário somente serão avaliados pelos pesquisadores envolvidos no projeto, não sendo permitido acesso a terceiros. Se desejar, a senhora poderá interromper sua participação a qualquer momento, sem ter que dar explicações, com a garantia de que não haverá qualquer prejuízo à sua pessoa, nem ao seu tratamento neste hospital.

\section{PREPARO PARA EXAMES A SEREM REALIZADOS DURANTE A PESQUISA}

\section{Bioimpedância Elétrica:}

A senhora deverá estar em jejum de no mínimo 12 horas, bem hidratada (consumo de 2 a 4 copos de água aproximadamente, 2 horas antes do teste, e esvaziar a bexiga exatamente antes), sem realização de exercício nas 4 a 6 horas anteriores e sem consumir álcool e café nas últimas 24 horas anteriores ao exame.

\section{Calorimetria Indireta:}

A senhora não deverá consumir café no dia anterior ao do teste, não deverá consumir álcool nas 48 horas antecedentes, não poderá realizar exercícios físicos 24 horas antes dos testes e deverá evitar a ingestão de água duas horas antes do teste. É necessário ainda que a senhora esteja em jejum de no mínimo 12 horas e que tenha dormido de seis a 
oito horas na noite anterior em que o exame será realizado. A senhora precisará permanecer em repouso por 30 minutos, deitada em uma maca, para depois ser feita a mensuração do seu Gasto Energético de Repouso durante 30 minutos, deitada, sem se movimentar e acordada.

Análise bioquímica e da concentração sérica de hormônios gastrointestinais:

A senhora deverá comparecer ao laboratório do HUB em jejum de 12 horas.

Atenciosamente,

Pesquisadora Responsável - Daniela Lopes Gomes

Doutoranda do Programa de Pós Graduação em Nutrição Humana

Contatos: (61)8214-4342 / email: dani_dlgomes@yahoo.com.br

Coordenadora do Projeto e orientadora - Profa Kenia Mara Baiocchi de Carvalho Departamento de Nutrição da UnB / Contatos: (61)81277427 / email: kenia@unb.br

\section{CONSENTIMENTO LIVRE E ESCLARECIDO}

Declaro que li as informações acima sobre a pesquisa, que me sinto perfeitamente esclarecida sobre o conteúdo da mesma, assim como seus riscos e benefícios. Declaro ainda que, por minha livre vontade, aceito participar da pesquisa cooperando com a coleta de dados para análise.

Brasília,

ASSINATURA DA PARTICIPANTE

Comitê de Ética em Pesquisa com Seres Humanos da Fundação de Ensino e Pesquisa em Ciências da Saúde (FEPECS) SMHN Quadra 03, conjunto A, Bloco 1 Edifício FEPECS tel.: 33254956 - CEP 70710-907 Brasília/DF. 


\section{APÊNDICE B \\ Questionário de dados sociodemográficos e antropométricos}

QUESTIONÁRIO DE DADOS SOCIODEMOGRÁFICOS

Protocolo:

Data da coleta:

Grupo: ( ) Controle ( ) Intervenção Hospital: ( ) HUB

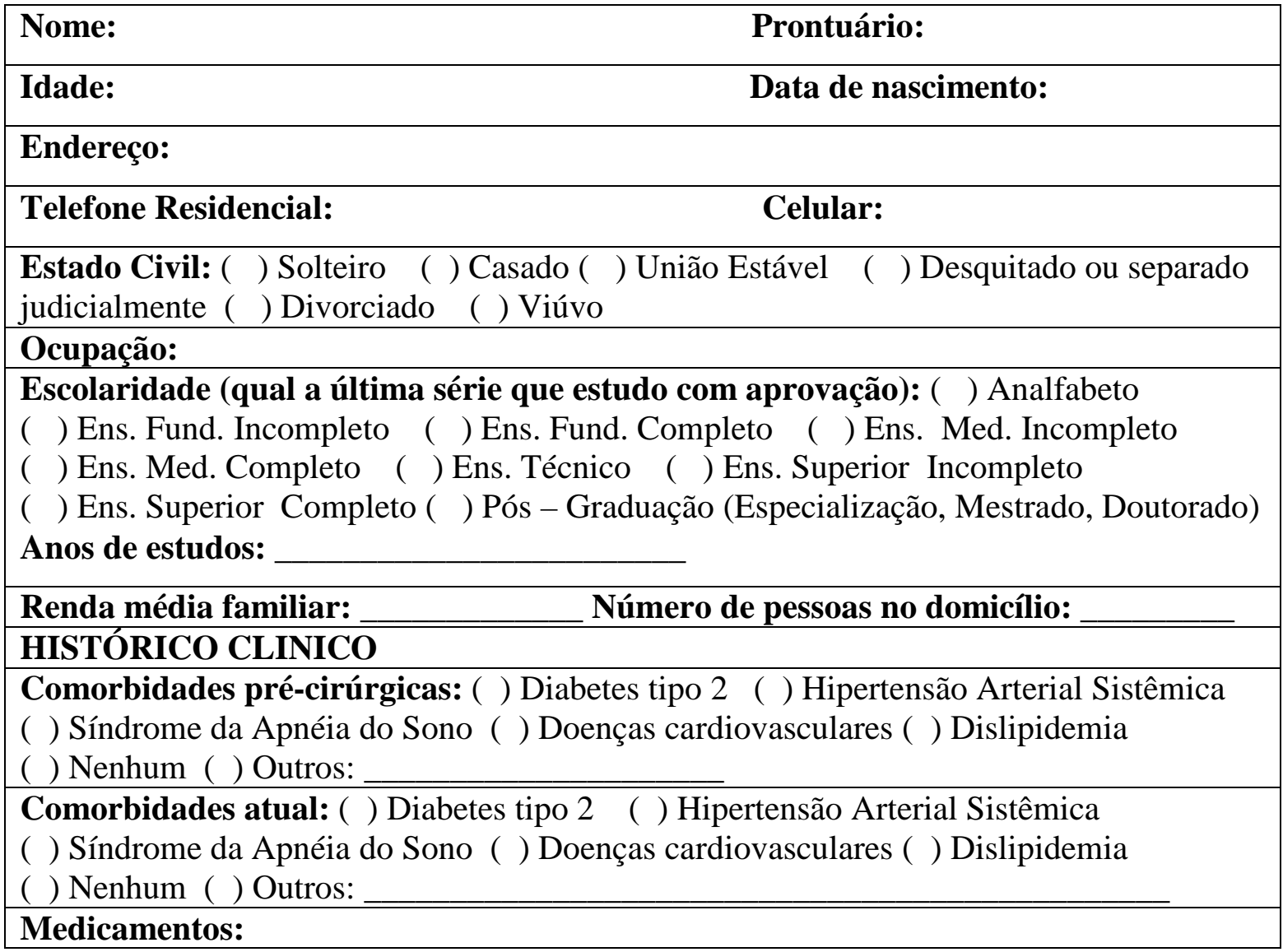

FORMULÁRIO DE REGISTRO DE DADOS ANTROPOMÉTRICOS

\begin{tabular}{|l|l|l|}
\hline ANTROPOMETRIA & \multicolumn{2}{|l|}{} \\
\hline Data da cirurgia & \multicolumn{2}{|l|}{} \\
\hline Peso pré-cirúrgico & \multicolumn{3}{|c|}{$\%$} \\
\hline Menor peso alcançado & \multicolumn{3}{|c|}{$\mathrm{kg}$} & \\
\hline Reganho & & \multicolumn{2}{|c|}{} \\
\hline Estatura & \multicolumn{2}{|c|}{} \\
\hline Peso atual & \\
\hline
\end{tabular}




\section{APÊNDICE C}

\section{Questionário de frequência alimentar diferenciado}

NOME:

Número:

DATA:

\begin{tabular}{|c|c|c|c|c|c|c|c|c|c|}
\hline \multirow[b]{2}{*}{ Produto } & \multirow[b]{2}{*}{$\begin{array}{c}\text { Porção } \\
\text { consumida } \\
\text { (n⿳亠丷厂犬descrição) }\end{array}$} & \multicolumn{8}{|c|}{ FREQUÊNCIA } \\
\hline & & $\begin{array}{c}2 \text { ou } \\
\text { mais } \\
\text { vezes } \\
\text { por dia }\end{array}$ & $\begin{array}{l}1 \mathrm{vez} \\
\text { por } \\
\text { dia }\end{array}$ & $\begin{array}{c}5 \text { a } 6 \\
\text { vezes } \\
\text { por } \\
\text { semana }\end{array}$ & $\begin{array}{c}2 \text { a } 4 \\
\text { vezes } \\
\text { por } \\
\text { semana }\end{array}$ & $\begin{array}{c}1 \text { vez } \\
\text { por } \\
\text { semana }\end{array}$ & $\begin{array}{c}1 \text { a } 3 \\
\text { vezes } \\
\text { por } \\
\text { mês }\end{array}$ & $\begin{array}{l}\mathrm{R} \\
/ \\
\mathrm{N}\end{array}$ & $\begin{array}{l}\text { Qtd } \\
\text { g/ } \\
\text { ml }\end{array}$ \\
\hline
\end{tabular}

Primeiro nível

\begin{tabular}{|l|l|l|l|l|l|l|l|l|l|}
\hline Frango & & & & & & & & \\
\hline $\begin{array}{l}\text { Carne } \\
\text { Bovina }\end{array}$ & & & & & & & & \\
\hline $\begin{array}{l}\text { Carne } \\
\text { de porco }\end{array}$ & & & & & & & & \\
\hline Peixe & & & & & & & & \\
\hline $\begin{array}{l}\text { Queijo } \\
\text { tipo } \\
\text { prato }\end{array}$ & & & & & & & \\
\hline $\begin{array}{l}\text { Queijo } \\
\text { Branco }\end{array}$ & & & & & & & \\
\hline Leite & & & & & & & \\
\hline Iogure & & & & & & & & \\
\hline Feijão & & & & & & & & \\
\hline Ovos & & & & & & & & \\
\hline
\end{tabular}

Segundo nível

\begin{tabular}{|l|l|l|l|l|l|l|l|l|}
\hline $\begin{array}{l}\text { Frutas 1 } \\
\text { (melão, } \\
\text { melancia, } \\
\text { morango, } \\
\text { maça, } \\
\text { laranja, } \\
\text { pêra) }\end{array}$ & & & & & & & & \\
\hline $\begin{array}{l}\text { Fruta 2 } \\
\text { (Uva, } \\
\text { banana, } \\
\text { abacate, }\end{array}$ & & & & & & & & \\
manga) & & & & & & & & \\
\hline Hortaliças & & & & & & & \\
\hline Azeite & & & & & & & & \\
\hline
\end{tabular}


Terceiro nível

\begin{tabular}{|l|l|l|l|l|l|l|l|l|l|}
\hline Arroz & & & & & & & & & \\
\hline Macarrão & & & & & & & & & \\
\hline Pão & & & & & & & & & \\
\hline Batata/ \\
Macaxeira
\end{tabular}

Quarto nível

\begin{tabular}{|l|l|l|l|l|l|l|l|l|l|}
\hline $\begin{array}{l}\text { Manteiga/ } \\
\text { Margarina }\end{array}$ & & & & & & & & & \\
\hline Frituras & & & & & & & & & \\
\hline $\begin{array}{l}\text { Doces, } \\
\text { guloseimas }\end{array}$ & & & & & & & & & \\
\hline Açúcar & & & & & & & & & \\
\hline $\begin{array}{l}\text { Refrigerante/ } \\
\text { Suco } \\
\text { industrializado }\end{array}$ & & & & & & & & & \\
\hline $\begin{array}{l}\text { Bebida } \\
\text { alcoólica }\end{array}$ & & & & & & & & & \\
\hline
\end{tabular}

\begin{tabular}{|l|l|l|}
\hline \multicolumn{1}{|c|}{ Suplementação } & \multicolumn{1}{|c|}{ Uso } & Prescrição atual \\
\hline $\begin{array}{l}\text { Suplemento } \\
\text { multivitaminas e } \\
\text { minerais }\end{array}$ & ( ) Sim ( ) Não & \\
\hline Citrato de Cálcio & ( ) Sim ( ) Não & \\
\hline Vitamina B12 & ( ) Sim ( ) Não & \\
\hline Ferro & ( ) Sim ( ) Não & \\
\hline Vitamina D & ( ) Sim ( ) Não & \\
\hline Outros & \multicolumn{2}{|l}{} \\
\hline
\end{tabular}

Quantidade de água consumida no dia: 


\section{ANEXO A \\ Aprovação no Comitê de Ética e Pesquisa}

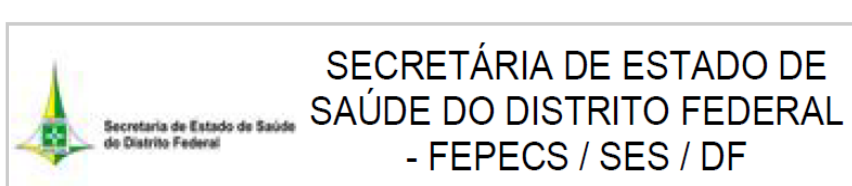

\section{PROJETO DE PESQUISA}

Título: Efeitos Metabólicos e Nutricionais da Suplementação Proteica em Pacientes com Dieta Hipoenergética para Tratamento de Reganho de Peso no Pós Operatório Tardio de Cirurgia Bariátrica

Área Temática:

Versão: 3

CAAE: $\quad 06228012.0 .0000 .5553$

Pesquisador: Daniela Lopes Gomes

Instituição: Hospital Regional da Asa Norte - HRAN

\section{PARECER CONSUBSTANCIADO DO CEP}

\begin{tabular}{lc}
\hline Número do Parecer: & 99.467 \\
Data da Relatoria: & $17 / 09 / 2012$
\end{tabular}

Apresentação do Projeto:

A Organização Mundial de Saúde (WHO, 1998) utiliza o Índice de Massa Corporal (IMC) para classificar a obesidade, que é um instrumento que avalia a obesidade global refletindo a proporção de tecido adiposo na massa corporal independente da localização. A OMS classifica o IMC em três níveis para a obesidade: obesidade grau I, com IMC entre 30 e $34,99 \mathrm{~kg} / \mathrm{m} 2$; obesidade grau II, com IMC entre 35 e 3 eficiente para que se alcance bons resultados. Assim, a terapêutica de pacientes obesos mórbidos passou a ser direcionada também à cirurgia bariátrica (EVANGELISTA; CAMPOS, 2011a)

\section{Objetivo da Pesquisa:}

Objetivo Primário:

Avaliar os resultados de dieta hipoenergética, associada à suplementação protéica nas concentrações séricas de hormônios gastrointestinais, gasto

energético de repouso, perda de peso e composição corporal em pacientes que obtiveram reganho de peso após 2 anos de realização da

Gastroplastia Redutora em Y de Roux (GRYR)

Objetivo Secundário:

- Verificar os efeitos do uso de suplementação proteica, em comparação a dieta normoproteica nas concentrações séricas de grelina, GLP-1, PYY e

insulina;- Avaliar a perda ponderal e evolução do gasto energético de repouso e da composição corporal dos participantes, durante o período de

tratamento;- Verificar a associação entre o consumo de proteína e massa magra corporal, o gasto energético de repouso e as concentrações séricas

de hormônios gastrointestinais

ica o IMC em três

níveis para a obesidade: obesidade grau I, com IMC entre 30 e $34,99 \mathrm{~kg} / \mathrm{m} 2$; obesidade grau II, com IMC entre

35 e 3 eficiente para que se alcance bons resultados. Assim, a terapêutica de pacientes obesos mórbidos passou a ser direcionada também à cirurgia bariátrica (EVANGELISTA; CAMPOS, 2011a)

\section{Avaliação dos Riscos e Benefícios:}

Riscos:

Serão mínimos os riscos à integridade física ou emocional dos participantes deste estudo. O participante poderá desistir a qualquer momento, no

Endereço: SMHN 2 Qd 501 BLOCO A - FEPECS

Bairro: ASA NORTE

UF: DF Município: BRASILIA

Telefone: (61)3325-4955 Fax: (33)3325-4955 E-mail: cepsesdf@saude.df.gov.br 


\section{S SECRETÁRIA DE ESTADO DE SAÚDE DO DISTRITO FEDERAL - FEPECS / SES / DF}

decorrer do estudo, sem que sofra qualquer tipo de prejuízo no seu tratamento.

Benefícios:

No que diz respeito aos benefícios, espera-se que o estudo contribua para uma avaliação clínica e nutricional minuciosa das participantes e

promoção de perda de peso saudável, prevenindo o desenvolvimento ou piora do quadro de comorbidades e melhorando a qualidade de vida dos

participantes. O acompanhamento nutricional sistemático, incluindo parâmetros metabólicos, permitem uma análise mais detalhada da evolução

clínica, do que a realizada apenas por consultas e exames de rotina. Os casos em que forem identificados problemas emocionais serão

encaminhados para psicoterapia. Assim, garante-se uma avaliação ampla e assistência integral aos pacientes que participarem do protocolo. Os

resultados da pesquisa serão entregues aos participantes por meio de encontro presencial ao final da pesquisa. Metodologia de Análise de Dados:

\section{Comentários e Considerações sobre a Pesquisa:}

Trata-se de estudo de intervenção, randomizado, controlado, com duração de 16 semanas. Os pacientes serão captados dos serviços de cirurgia

bariátrica do Hospital Regional da Asa Norte (HRAN) e Hospital Universitário de Brasília (HUB). Serão incluídos

60 pacientes de 18 a 55 anos, do

sexo feminino, submetidas a cirurgia de gastroplastia redutora com derivação gastro jejunal em Y de Roux há mais de 24 meses e que apresentaram

reganho de peso de no mínimo $5 \%$ do menor peso alcançado durante o tratamento. Serão excluídas aquelas com diabetes descompensada, em

tratamento hormonal, nefropatas, hepatopatas ou em uso de alguma medicação para emagrecimento Os pacientes serão aleatoriamente alocados

no grupo de intervenção (dieta hipoenergética, com suplementação de $1 \mathrm{~g} / \mathrm{kgP}$ ideal de albumina em pó) ou grupo controle (dieta hiponergética).

Serão aplicados questionários com questões

Tamanho da Amostra no Brasil: 60

Considerações sobre os Termos de apresentação obrigatória:

APRESENTADOS

Recomendações:

Conclusões ou Pendências e Lista de Inadequações:

APROVADO

Situação do Parecer:

Aprovado

Necessita Apreciação da CONEP:

Não

Considerações Finais a critério do CEP:

Aprovado

Endereço: SMHN 2 Qd 501 BLOCO A - FEPECS

Bairro: ASA NORTE

UF: DF Município: BRASILIA

CEP: $70.710-904$

Telefone: (61)3325-4955 Fax: $\quad$ (33)3325-4955

E-mail: cepsesdf@saude.df.gov.br 


\section{Questionário de Atividade Física (Vigitel)}

NOME: NÚMERO:

DATA:

Q1. Nos últimos três meses, o(a) $\operatorname{Sr}($ a) praticou algum tipo de exercício físico ou esporte? ( ) Sim ( ) Não

Q2. Qual?

( ) Caminhada (não vale deslocamento para trabalho)

( ) Caminhada na esteira

( ) Corrida

( ) Musculação

( ) Ginástica aeróbica (spinning, step, jump)

( ) Hidroginástica

( ) Ginástica em geral

( ) Natação

( ) Artes marciais e luta (jiu-jstu, caratê, judô)

( ) Bicicleta

( ) Futebol

( ) Basquetebol

( ) Voleibol

( ) Tênis

( ) Outros Qual:

Q3. O(a) Sr(a) pratica o exercício pelo menos uma vez por semana?

( ) Sim ( ) Não - (pule para Q6)

Q4. Quantos dias na semana por semana o(a) $\operatorname{Sr}(a)$ costuma praticar exercício físico ou esporte? dias

Q5. No dia que o(a) Sr(a) costuma praticar exercício físico ou esporte, quanto tempo dura esta atividade? minutos

Q6. Nos últimos três meses, o(a) Sr(a) trabalhou?

( ) Sim ( ) Não - (pule para Q10) 
Q7. No seu trabalho, anda bastante a pé?

( ) Sim ( ) Não

Q8. No seu trabalho, o(a) Sr(a) carrega peso ou faz outra atividade pesada?

( ) $\operatorname{Sim}($ ) Não

Q9. Para ir ou voltar ao seu trabalho, escola e/ou compras faz algum trajeto a pé ou de bicicleta?

( ) Sim ( ) Não

Q10. Quanto tempo por dia, o (a) Sr (a) gasta para ir e voltar nesse trajeto? minutos

Q11. Você costuma fazer a faxina da sua casa sozinho?

( ) Sim - (pule Q13) ( ) Não

Q12. A parte mais pesada da faxina fica com:

( ) Você ( ) Outra pessoa ( ) Ambos

Q13. Em média, quantas horas por dia o(a) Sr(a) costuma ficar assistindo televisão/internet?

horas 
ANEXO C

Questionário dos Três Fatores Alimentares (TFEQ-R21)

NOME:

$\mathbf{n}^{\mathbf{o}}$

\begin{tabular}{|c|c|}
\hline $\begin{array}{l}\text { 1. Por conta própria você consume pequenas porções de alimentos para controlar } \\
\text { seu peso. } \\
\text { ( ) Totalmente verdade (4) } \\
\text { ( ) Verdade, na maioria das vezes (3) } \\
\text { ( ) Falso, na maioria das vezes (2) } \\
\text { ( ) Totalmente falso (1) }\end{array}$ & $1 \square$ \\
\hline $\begin{array}{l}\text { 2. Você começa a comer quando se sente ansiosa. } \\
\text { ( ) Totalmente verdade (4) } \\
\text { ( ) Verdade, na maioria das vezes (3) } \\
\text { ( ) Falso, na maioria das vezes (2) } \\
\text { ( ) Totalmente falso (1) }\end{array}$ & $2 \square$ \\
\hline $\begin{array}{l}\text { 3. Ás vezes, quando você começa a comer, parece que não conseguirá parar. } \\
\text { ( ) Totalmente verdade (4) } \\
\text { ( ) Verdade, na maioria das vezes (3) } \\
\text { ( ) Falso, na maioria das vezes (2) } \\
\text { ( ) Totalmente falso (1) }\end{array}$ & $3 \square$ \\
\hline $\begin{array}{l}\text { 4. Quando você se sente triste, frequentemente come demais. } \\
\text { ( ) Totalmente verdade (4) } \\
\text { ( ) Verdade, na maioria das vezes (3) } \\
\text { ( ) Falso, na maioria das vezes (2) } \\
\text { ( ) Totalmente falso (1) }\end{array}$ & $4 \square$ \\
\hline $\begin{array}{l}\text { 5. Você não come alguns alimentos porque eles engordam. } \\
\text { ( ) Totalmente verdade (4) } \\
\text { ( ) Verdade, na maioria das vezes (3) } \\
\text { ( ) Falso, na maioria das vezes (2) } \\
\text { ( ) Totalmente falso (1) }\end{array}$ & $5 \square$ \\
\hline $\begin{array}{l}\text { 6. Estar com alguém que está comendo dá, frequentemente, vontade de comer } \\
\text { também. } \\
\text { ( ) Totalmente verdade (4) } \\
\text { ( ) Verdade, na maioria das vezes (3) } \\
\text { ( ) Falso, na maioria das vezes (2) } \\
\text { ( ) Totalmente falso (1) }\end{array}$ & $6 \square$ \\
\hline $\begin{array}{l}\text { 7. Quando se sente tensa ou estressada, frequentemente sente que precisa comer. } \\
\text { ( ) Totalmente verdade (4) } \\
\text { ( ) Verdade, na maioria das vezes (3) } \\
\text { ( ) Falso, na maioria das vezes (2) } \\
\text { ( ) Totalmente falso (1) }\end{array}$ & \begin{tabular}{|l|}
$7 \square$ \\
\end{tabular} \\
\hline
\end{tabular}




\begin{tabular}{|c|c|}
\hline $\begin{array}{l}\text { 8. Frequentemente, sente tanta fome que seu estômago parece um poço sem fundo. } \\
\text { ( ) Totalmente verdade (4) } \\
\text { ( ) Verdade, na maioria das vezes (3) } \\
\text { ( ) Falso, na maioria das vezes (2) } \\
\text { ( ) Totalmente falso (1) }\end{array}$ & $8 \square$ \\
\hline $\begin{array}{l}\text { 9. Você sempre está com tanta fome que é difícil parar de comer antes de terminar } \\
\text { toda a comida que está no prato. } \\
\text { ( ) Totalmente verdade (4) } \\
\text { ( ) Verdade, na maioria das vezes (3) } \\
\text { ( ) Falso, na maioria das vezes (2) } \\
\text { ( ) Totalmente falso (1) }\end{array}$ & 9ロ \\
\hline $\begin{array}{l}\text { 10. Quando se sente solitária, se consola comendo. } \\
\text { ( ) Totalmente verdade (4) } \\
\text { ( ) Verdade, na maioria das vezes (3) } \\
\text { ( ) Falso, na maioria das vezes (2) } \\
\text { ( ) Totalmente falso (1) }\end{array}$ & 10ם \\
\hline $\begin{array}{l}\text { 11. Você, conscientemente, se controla nas refeições para evitar ganhar peso. } \\
\text { ( ) Totalmente verdade (4) } \\
\text { ( ) Verdade, na maioria das vezes (3) } \\
\text { ( ) Falso, na maioria das vezes (2) } \\
\text { ( ) Totalmente falso (1) }\end{array}$ & 11口 \\
\hline $\begin{array}{l}\text { 12. Quando sente o cheiro de um bife grelhado ou de um pedaço suculento de } \\
\text { carne, acho muito difícil evitar de comer, mesmo que tenha terminado de comer há } \\
\text { muito pouco tempo. } \\
\text { ( ) Totalmente verdade (4) } \\
\text { ( ) Verdade, na maioria das vezes (3) } \\
\text { ( ) Falso, na maioria das vezes (2) } \\
\text { ( ) Totalmente falso (1) }\end{array}$ & $12 \square$ \\
\hline $\begin{array}{l}\text { 13. Você sempre está com tanta fome o bastante para comer a qualquer hora. } \\
\text { ( ) Totalmente verdade (4) } \\
\text { ( ) Verdade, na maioria das vezes (3) } \\
\text { ( ) Falso, na maioria das vezes (2) } \\
\text { ( ) Totalmente falso (1) }\end{array}$ & 13ם \\
\hline $\begin{array}{l}\text { 14. Se você se sente nervosa, tenta acalmar comendo. } \\
\text { ( ) Totalmente verdade (4) } \\
\text { ( ) Verdade, na maioria das vezes ( } 3 \text { ) } \\
\text { ( ) Falso, na maioria das vezes (2) } \\
\text { ( ) Totalmente falso (1) }\end{array}$ & 14ロ \\
\hline $\begin{array}{l}\text { 15. Quando vê algo que parece muito delicioso, frequentemente fica com tanta } \\
\text { fome que tem que comer imediatamente. } \\
\text { ( ) Totalmente verdade (4) } \\
\text { ( ) Verdade, na maioria das vezes (3) } \\
\text { ( ) Falso, na maioria das vezes (2) } \\
\text { ( ) Totalmente falso (1) }\end{array}$ & 15口 \\
\hline $\begin{array}{l}\text { 16. Quando se sente depressiva, quer comer. } \\
\text { ( ) Totalmente verdade (4) } \\
\text { ( ) Verdade, na maioria das vezes (3) } \\
\text { ( ) Falso, na maioria das vezes (2) } \\
\text { ( ) Totalmente falso (1) }\end{array}$ & $16 \square$ \\
\hline
\end{tabular}




\begin{tabular}{|c|c|}
\hline $\begin{array}{l}\text { 17. O quanto frequentemente você evita guardar (fazer estoque, guardar em casa) } \\
\text { comidas tentadoras? } \\
\text { ( ) Quase nunca (1) } \\
\text { ( ) Raramente (2) } \\
\text { ( ) Frequentemente (3) } \\
\text { ( ) Quase sempre (4) }\end{array}$ & 17ロ \\
\hline $\begin{array}{l}\text { 18. O quanto você estaria disposto a fazer um esforço para comer menos do que } \\
\text { deseja? } \\
\text { ( ) Não estou disposto (1) } \\
\text { ( ) Estou um pouco disposto (2) } \\
\text { ( ) Estou relativamente bem disposto (3) } \\
\text { ( ) Estou muito disposto (4) }\end{array}$ & $18 \square$ \\
\hline $\begin{array}{l}\text { 19. Você comete excessos alimentares, mesmo quando não está com fome? } \\
\text { ( ) Quase nunca (1) } \\
\text { ( ) Raramente (2) } \\
\text { ( ) Às vezes (3) } \\
\text { ( ) Pelo menos } 1 \text { vez por semana (4) }\end{array}$ & 19ロ \\
\hline $\begin{array}{l}\text { 20. Com qual frequência você fica com fome? } \\
\text { ( ) Somente nos horários das refeições (1) } \\
\text { ( ) As vezes entre as refeições (2) } \\
\text { ( ) Frequentemente entre as refeições (3) } \\
\text { ( ) Quase sempre (4) }\end{array}$ & $20 \square$ \\
\hline $\begin{array}{l}\text { Em uma escala de } 1 \text { a } 8 \text { em que } 1 \text { significa nenhuma restrição alimentar e } 8 \\
\text { significa restrição total, qual número você daria para si mesmo? } \\
\text { ( ) } 1 \text { (1) } \\
\text { ( ) } 2(1) \\
\text { ( ) } 3(2) \\
\text { ( ) } 4(2) \\
\text { ( ) } 5(3) \\
\text { ( ) } 6(3) \\
\text { ( ) } 7(4) \\
\text { ( ) } 8 \text { (4) }\end{array}$ & $21 \square$ \\
\hline $\begin{array}{l}1 \text { Significa: Eu como tudo o que qu } \\
8 \text { significa: Eu limito constantemen }\end{array}$ & \\
\hline
\end{tabular}

